\title{
From Concept to Design: Progress on the J-2X Upper Stage Engine for the Ares Launch Vehicles
}

\author{
Thomas Byrd, Deputy Manager, J-2X Upper Stage Engine Element \\ Ares Projects Office \\ Marshall Space Flight Center \\ Huntsville, AL 35812
}

\begin{abstract}
In accordance with national policy and NASA's Global Exploration Strategy, the Ares Projects Office is embarking on development of a new launch vehicle fleet to fulfill the national goals of replacing the space shuttle fleet, returning to the moon, and exploring farther destinations like Mars. These goals are shaped by the decision to retire the shuttle fleet by 2010 , budgetary constraints, and the requirement to create a new fleet that is safer, more reliable, operationally more efficient than the shuttle fleet, and capable of supporting long-range exploration goals. The present architecture for the Constellation Program is the result of extensive trades during the Exploration Systems Architecture Study and subsequent refinement by the Ares Projects Office at Marshall Space Flight Center.
\end{abstract}

The vehicles selected to support those goals are the Ares I crew launch vehicle and the Ares V cargo launch vehicle, the first new human-rated launch vehicles developed by NASA in more than three decades (Figure 1). Ares I will begin its initial operating capability of flying up to six astronauts to the International Space Station (ISS) no later than 2015. Ares V is scheduled to be operational in the 2020 timeframe to support lunar missions.

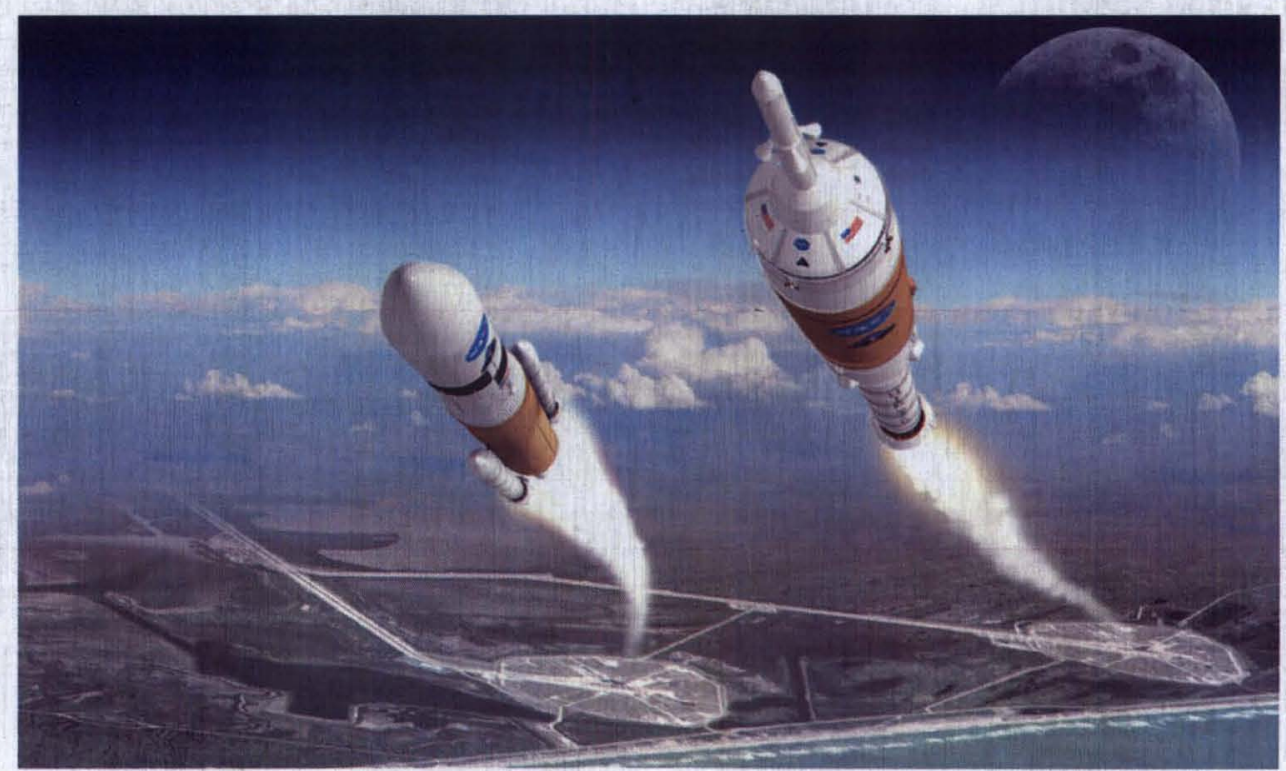

Figure 1. The Ares V Cargo Launch Vehicle (left) and Ares I Crew Launch Vehicle (right) will form the backbone of America's new space fleet. (NASA artist's concept)

The reference lunar mission would begin by launching the Ares V, carrying the Lunar Lander, into orbit to be checked out before the launch of the crew aboard the Ares I. The Ares V first stage propulsion system consists of a core stage powered by five commercial liquid hydrogen/liquid oxygen $\left(\mathrm{LH}_{2} / \mathrm{LOX}\right)$ 
RS-68 engines, flanked by two five-segment solid rocket boosters (SRBs). Atop the core stage is the Earth departure stage (EDS), powered by powered by a single J-2X upper stage engine, and a payload shroud enclosing the lunar lander. The EDS/lunar lander will go into a stable checkout orbit. The Ares I, carrying the Orion crew exploration vehicle, will follow the Ares V into orbit. The Ares I first stage consists of a single five-segment SRB. Once that stage is expended during launch, the upper stage, powered, by a single J-2X, will ignite to take the Orion into orbit. The upper stage is then expended. After Orion docks with the EDS/lander, the J-2X will ignite a second time to begin trans-lunar injection (TLI).The EDS would be discarded at the end of the TLI burn. The Orion and Lunar Lander perform the remainder of the mission, with Orion remaining in lunar orbit autonomously while the crew descends to the Moon in the lander. At the end of the surface stay, the crew returns to Orion in the lander ascent stage, which is then discarded. The crew returns to Earth in the Orion crew module for reentry and landing.

\section{Engine Requirements and Design Drivers}

The J-2X exemplifies Constellation program goals of seeking commonality between the Ares I and Ares $\mathrm{V}$ and using heritage hardware and knowledge to streamline the hardware development approach and reduce programmatic, technical, and budget risks. The prime contractor for the J-2X is Pratt \& Whitney Rocketdyne (PWR), which is under a design, development, test and engineering (DDT\&E) contract that covers the period from early 2006 to the end of 2012.

For Ares I, the $\mathrm{J}-2 \mathrm{X}$ will provide an engine start at altitude and then second-stage propulsion for a nominal burn period of 500 seconds. For Ares V, the J-2X will provide an engine start at altitude, operation of roughly 500 seconds for second stage propulsion, engine shutdown, on-orbit loiter for up to 95 days, on-orbit restart upon command, engine operation for roughly 300 seconds in secondary mode at reduce thrust level to execute TLI, and final engine shutdown. Requirements are summarized in Figure 2 below.

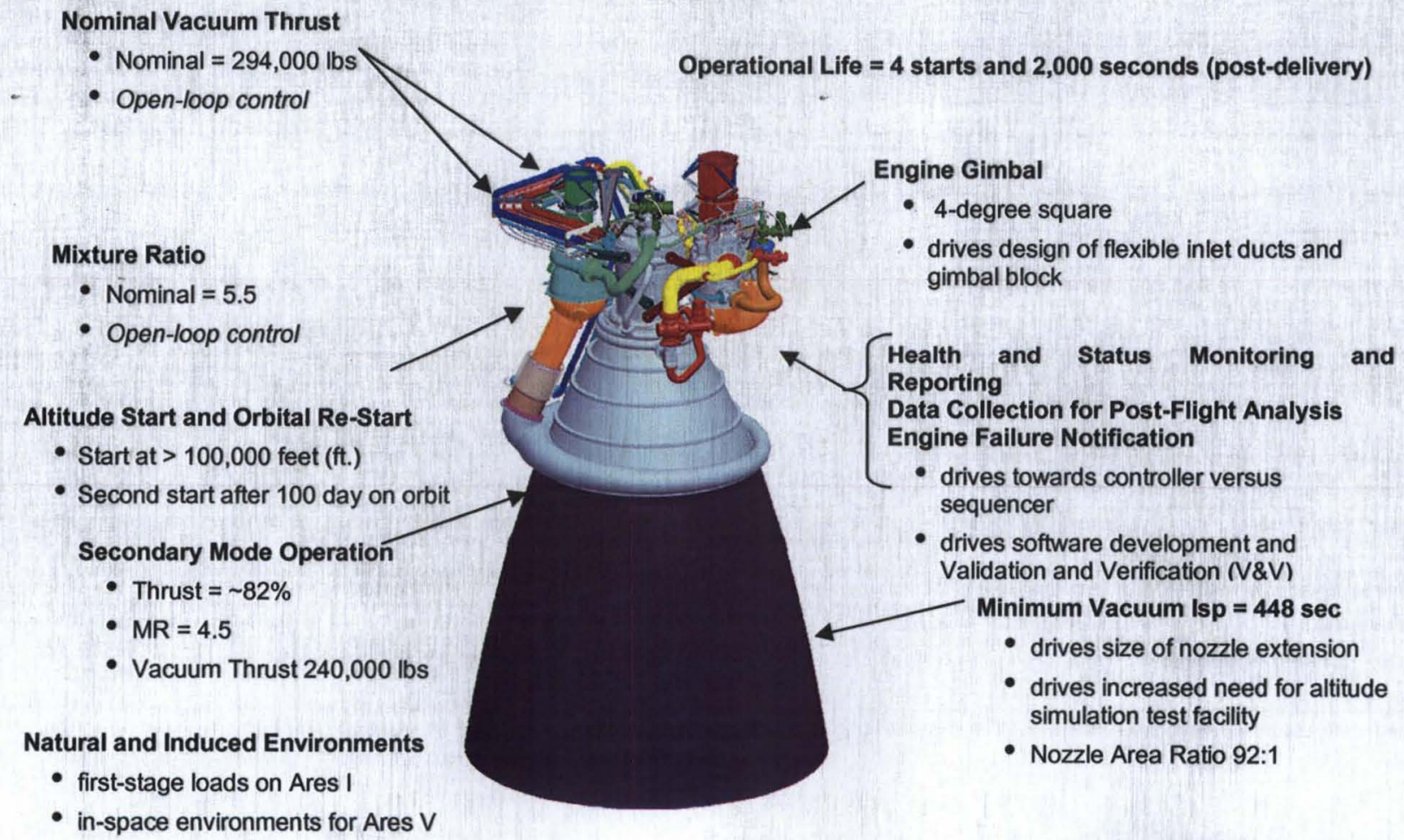

Figure 2. J-2X Key Requirements. 
The J-2X leverages PWR's flight-proven $\mathrm{LH}_{2} / \mathrm{LOX}$, gas generator cycle J-2 and RS-68 engine capabilities, recent experience with the X-33 aerospike XRS-2200 engine, and development knowledge of the J-2S tap-off cycle engine. The Ares I and Ares V missions require that the J-2X operate at much higher temperatures, pressures, and flow rates than the heritage J-2, making it one of the highest performing gas generator cycle engines ever built, approaching the efficiency of more complex staged combustion engines such as the Space Shuttle Main Engine.

The heritage Saturn Apollo J-2 provided 230,000 pounds of thrust at a specific impulse of 425 seconds. Using a $\mathrm{LH}_{2} / \mathrm{LOX}$ propellant combination, the J-2X gas generator power cycle is designed to produce 294,000 pounds-force ( $(\mathrm{bf})$ of thrust at a minimum vacuum specific impulse of 448 seconds. It can be operated at two thrust levels, called "primary" and "secondary" mode. The primary mode mixture ratio is 5.5 , while secondary mode uses a mixture ratio of 4.5 to deliver roughly $82 \%$ of primary mode thrust. Primary mode thrust will be used for the ascent burn on both Ares I and Ares V. Secondary thrust mode is for the TLI burn on Ares V due to load limitations on the Orion-to-lunar lander docking system.

Ares I requirements drive the J-2X thrust requirement, while Ares $\mathrm{V}$ requirements drive the engine's specific impulse performance. Both must be balanced against schedule, cost, weight and volume factors. Other changes reflect contemporary manufacturing techniques and materials, as well as post-Apollo engine design and analysis techniques.

Turbomachinery is the critical path on the design schedule. NASA managers chose to mitigate schedule risk by starting with the J-2S Mk. 29 turbopump design as their point-of-departure, deviating only as needed to meet performance requirements, design criteria, and modern materials selection. The thrust requirement is an increase of more than 25 percent from the heritage $\mathrm{J}-2$, requiring greater flow through the turbopumps. Keeping with the J-2S point-of-departure, the single-stage fuel turbopump design limits the discharge pressure, and, thus, the main chamber pressure. To achieve 448 seconds of specific impulse, the gas generator engine cycle requires a high area ratio from the nozzle exit to the main combustion chamber throat. Engine weight requirements constrain the nozzle design, so the area ratio demands a regeneratively-cooled nozzle, augmented by a nozzle extension cooled by radiation and turbine exhaust gas. Nozzle extension weight and cooling concerns resulted in changing from metal to composite materials. The Ares I vehicle envelope constrains the nozzle extension diameter, thus, constraining the throat diameter, which, in turn, drives chamber pressure up. The resultant chamber pressure is a balance between fuel pump single stage limitations and nozzle extension diameter limitations. The current design heritage is shown in Figure 3 below. 
Turbomachinery

- Based on J-2S MK-29 design

- Beefed up to meet J-2X performance

- Altered to meet current NASA design standards

- Helium Spin Start

Gas Generator

- Based on RS-68 design

- Scaled to meet J-2X needs

- Pyrotechnic Igniter

Engine Controller

- Based on directly on RS-68 design and software architecture

Tube-Wall Regeneratively-

Cooled Nozzle Section

- Based on long history of RS-27 success (Delta II/III)

Heat Exchanger

- Based on $\mathrm{J}-2$ experience on as used on S-IVB

\section{Gimbal Block}

- Based on J-2 \& J-2S design

- Potential upgrade to more modern, demonstrated materials

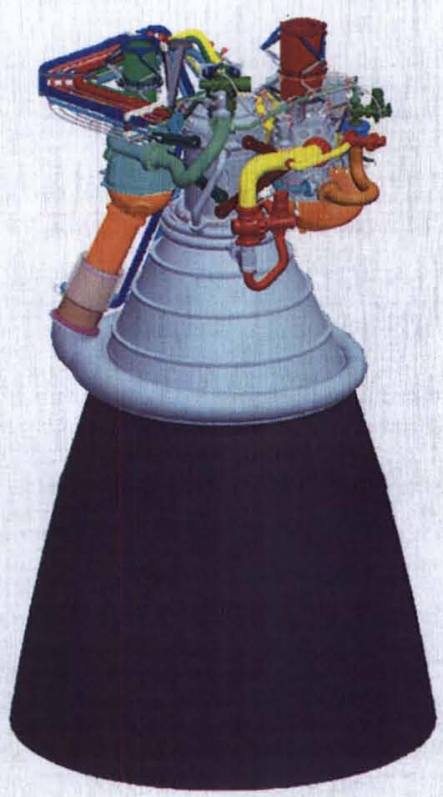

\section{Flexible Inlet Ducts}

- Based on J-2 \& J-2S ducts

- Adjusted to meet J-2X performance

- Altered to meet current NASA design standards

Open Loop Pneumatic Control

- Similar to J-2 \& J-2S design Valves

- Ball sector traceable to XRS2200 and RS-68

Main Injector

- Based on RS-68 design to meet Isp

- Augmented Spark Igniter

HIP-bonded MCC

- Based on RS-68 demonstrated technology

Nozzle Extension

- Based on RL10-B2 experience

Figure 3. J-2X Design Heritage.

\section{Design Evolution Avoids 'Clean Sheet' Engine}

The heritage $\mathrm{J}-2$, as anticipated, served as a point-of-departure for the $\mathrm{J}-2 \mathrm{X}$ configuration and effectively constitutes a new development program. As previously mentioned, the Ares vehicle requirements and Ares/Orion lunar exploration missions are considerably more demanding than Saturn/Apollo. The requirement for greater mass delivered to the lunar surface is largely responsible for the higher $\mathrm{J}-2 \mathrm{X}$ thrust and specific impulse requirements. The $\mathrm{J}-2 \mathrm{X}$ also must meet greater loss of mission reliability and numerous other requirements associated with human rating that were not applied to the original J-2; therefore, a re-manufactured J-2/J-2S engine was not an option.

Despite these requirements, the J-2X DDT\&E cycle lacks much of the risk associated with typical "new development" rocket engines. In the 40 years since the J-2 and J-2S were developed, many advances have occurred in rocket engine design and development to make the $\mathrm{J}-2 \mathrm{X}$ a better product than a re-manufactured $\mathrm{J}-2 / \mathrm{J}-2 \mathrm{~S}$. Indeed, many of the heritage materials and manufacturing methods are obsolete; many heritage suppliers no longer exist; limited design and qualification data are available; and many of the design engineers are no longer available. The result is replacement and/or modification of virtually every part derived from the $\mathrm{J}-2$ or $\mathrm{J}-2 \mathrm{~S}$ heritage designs. The $\mathrm{J}-2 \mathrm{X}$ design team understands the deviations from $\mathrm{J}-2$ and has methodically studied the heritage $\mathrm{J}-2$ design for its applicability to $\mathrm{J}-2 \mathrm{X}$ needs. The design team is deviating from heritage $\mathrm{J}-2$ only as needed and has a development plan that addresses these differences, leveraging technology and knowledge from more recent engines. 


\section{J-2X Development and Production}

The J-2X development effort focuses on four key areas, which represent a building-block approach to acquire empirical knowledge as the design and analysis of the engine mature:

- Early risk mitigation, including characterization of heritage turbomachinery and valves.

- Design risk mitigation, including characterization of various design features prior to component testing.

- Component and subassembly test.

- Engine system test, including development and certification, as well as support to the Ares I Upper Stage Main Propulsion Test Article (MPTA).

The development plans include testing engine components, including the subscale injector, igniter, powerpack assembly (turbopumps, gas generator and associated ducting and structural mounts), full-scale gas generator, valves, and control software with hardware-in-the-loop. The J-2X Element office was able to begin testing with heritage J-2 hardware at Marshall Space Flight center less than six months after the organization's inception. Testing in 2006 focused on injector and valve hardware (Figure 4).

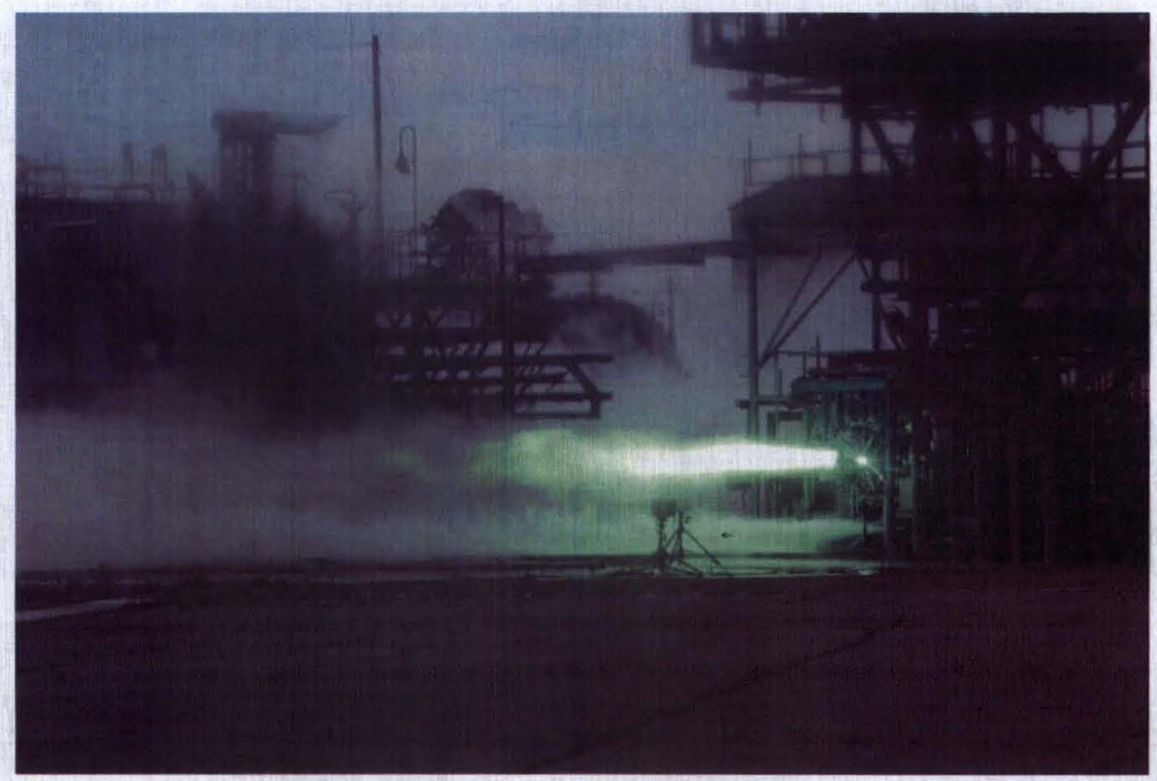

Figure 4. Subscale main injector test at Marshall.

To support the test program, NASA handed over the A-1 test stand at Stennis Space Center from the Space Shuttle Program to the Constellation Program in November 2006. Following site preparation work in early 2007, Stennis broke ground in June 2007 for a new altitude simulation test stand, designated A-3, in June 2007 (Figure 5). Discussions are under way to transfer the A-2 test stand from Shuttle to Constellation. Plans are also under way for a main propulsion test article (MPTA) stand at Marshall Space Flight Center to test the J-2X engine integrated with a ground test version of the Ares I upper stage. 


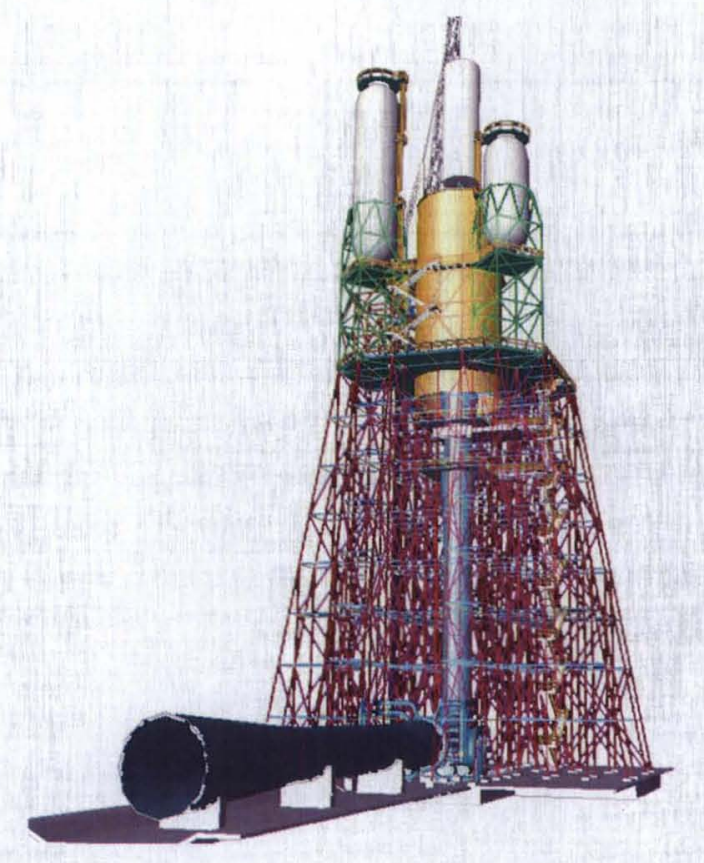

Figure 5. Artist's concept of A-3 test stand at SSC for J-2X altitude testing.

Analyses and testing conducted during 2006 and 2007 resulted in several changes to the baseline J-2X configuration, as well as test objectives. The J-2X Element office eliminated the parallel option for developing a 274,000-pound thrust engine for early International Space Station missions. More components trace their heritage to the new RS-68 engine scaled for J-2X application, including elimination of the original plan for a J-2 heritage gas generator. A channel wall nozzle design was replaced by a tube wall regeneratively cooled nozzle to accommodate the need for more uniform cooling. Despite higher development costs, composites were selected for the nozzle extension because of their significantly higher temperature margin. A turbine exhaust gas manifold was also added to the nozzle design to provide cooling, as well as extra specific impulse.

To refine the design details of the gas generator (GG), plans were added for a workhorse gas generator test series, using 43- and 61-element injectors to establish the final density and total number of elements on the full-scale injector. The workhorse hardware will include a turbine simulator - including ducting and orifice representative of the actual turbine back pressure - in an effort to understand turbine temperatures and resulting turbine blade durability. Several turbopump material and design changes were selected for improved strength, load reduction, rotor stability enhancement, improved fault tolerance, and ease of assembly and disassembly. Helium spin start for start and re-start was selected over solid propellant gas generators due to the potential for debris generation by the latter and lower development cost for the helium spin start system. Engineers retained the J-2 heritage 8-inch scissors ducts at the turbopump inlets. The team retained the baselined dual channel Engine Controller Unit, open loop control mode, and pneumatic valve actuation. However, as a result of heritage valve testing, the goal of using heritage butterfly valves for the main fuel, main oxidizer, gas generator fuel and oxidizer, and oxidizer turbopump bypass valves was dropped in favor of sector ball valves, where there was greater recent experience and potential for better control authority. Two additional turbo machinery spare sets and spares were added to the development project to allow for more flexibility in testing and accommodate hardware losses during testing. 
The first powerpack test series was scheduled to begin in fall 2007 on the A-1 test stand at Stennis Space Center (Figure 6). Objectives of this early series featuring heritage J-2 hardware include preparation and testing of the facility, obtaining inducer flow environments (with high-frequency pressures), and obtaining pump performance (with better temperature and pressure data). The turbo machinery development program in 2007 also included water flow testing of existing pump inlets, a turbine air flow test, and water flow tests of the inducers, which provided insights important to planning the powerpack series.

Production engines will be manufactured, assembled, and accepted (including hot fire) at Stennis Space Center (SSC), then shipped to Michoud Assembly Facility (MAF) for integration with the Ares I upper stage. Once integrated with upper stage, the engine will support any stage tests needed prior to shipping the engine/stage assembly to Kennedy Space Center (KSC). At KSC, the engine/stage assembly will be checked out, stacked on the vehicle, rolled to the launch pad, and prepared for launch operations. Following a Line Replaceable Unit (LRU) philosophy, the engine or some components may be removed and replaced for cause from an engine/stage assembly at KSC. Engine logistical support at KSC will include checkout and LRU spares, but no engine shop at KSC is planned for disassemblies. Removed engine hardware will typically be returned to the assembly facility at SSC, to PWR, or to a vendor.

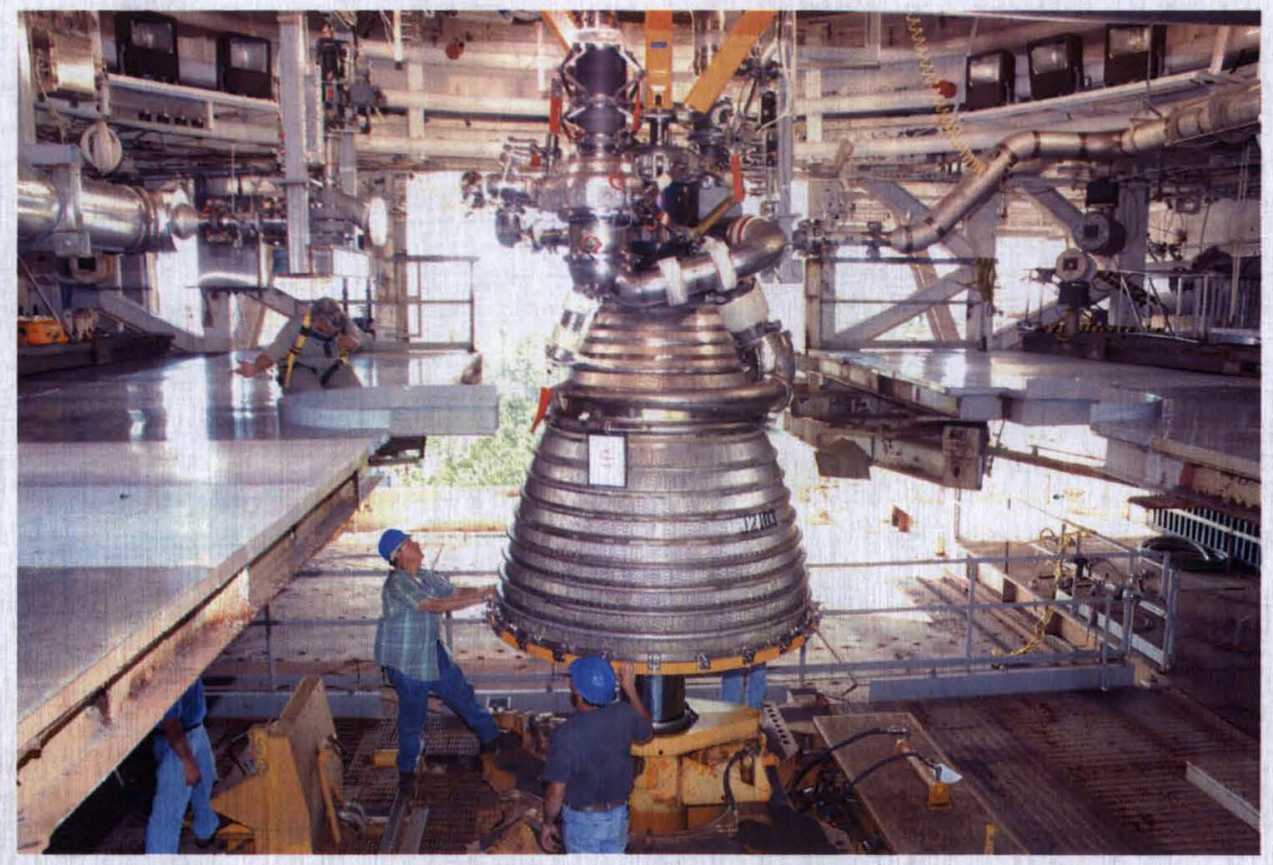

Figure 6. Powerpack 1A during test stand installation at Stennis Space Center.

\section{Conclusion}

NASA's Ares Projects Office is dedicated to designing the Ares I and Ares V launch vehicle systems for safety, simplicity, robust operability, and streamlined supportability to reduce operations costs, allowing NASA to focus more resources on exploration and discovery than on routine operations. The Ares Projects Office and the Upper Stage Engine Element will continue to reduce risks by drawing upon lessons learned in the past and applying modern engineering tools and processes. Hardware commonality between the two launch vehicles - as exemplified by the J-2X - will reduce the fleet's logistics footprint, as well as nonrecurring and fixed operations costs. The $\mathrm{J}-2 \mathrm{X}$ team will continue to emphasize a "test as you fly, fly what you test" development philosophy as it begins validating and verifying critical engine hardware. This team-based, test-based engineering strategy will help sustain long-term space exploration, expanding humanity's reach to the Moon, Mars, and beyond. 
From Concept to Design: Progress on the J-2X Upper Stage Engine for the Ares Launch Vehicles

AIAA Joint Propulsion Conference July 20-23, 2008

Tom Byrd Deputy Manager J-2X Upper Stage Engine Element Ares Projects Office Marshall Space Flight Center, NASA

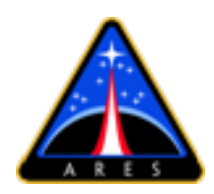



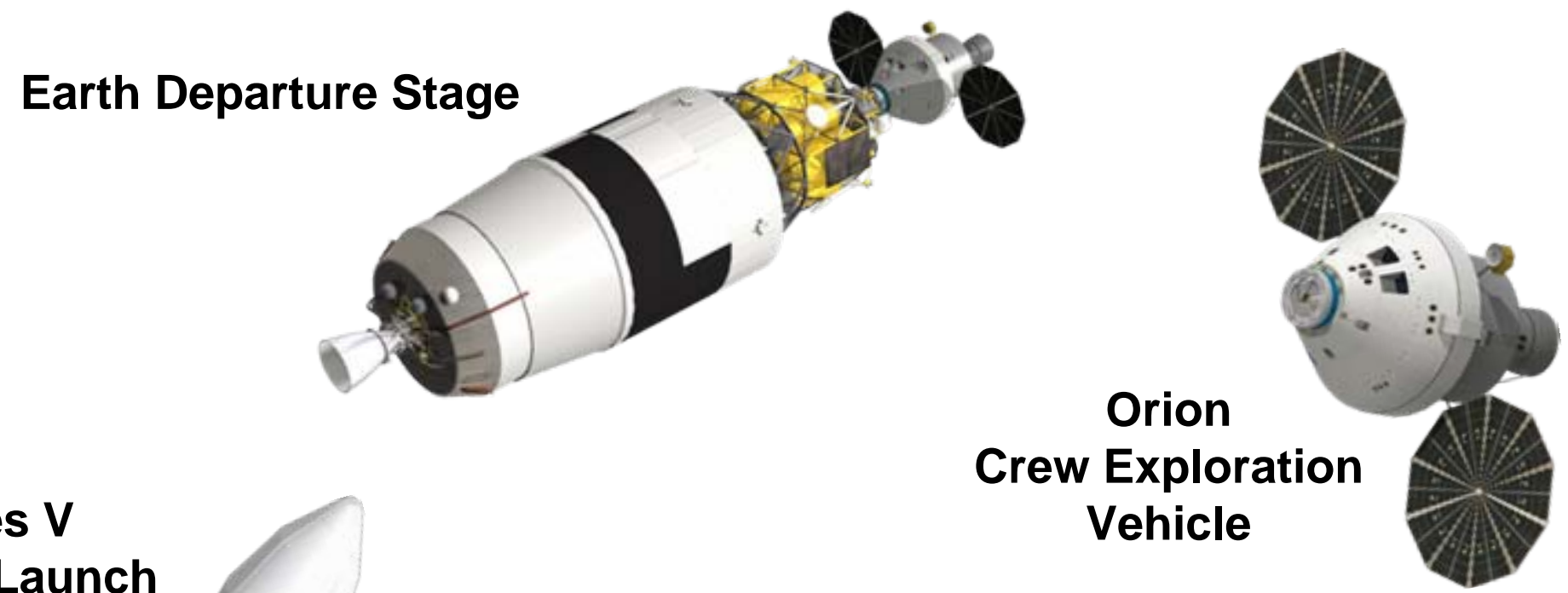

Cargo Launch

Vehicle

Ares I

Crew Launch

Vehicle

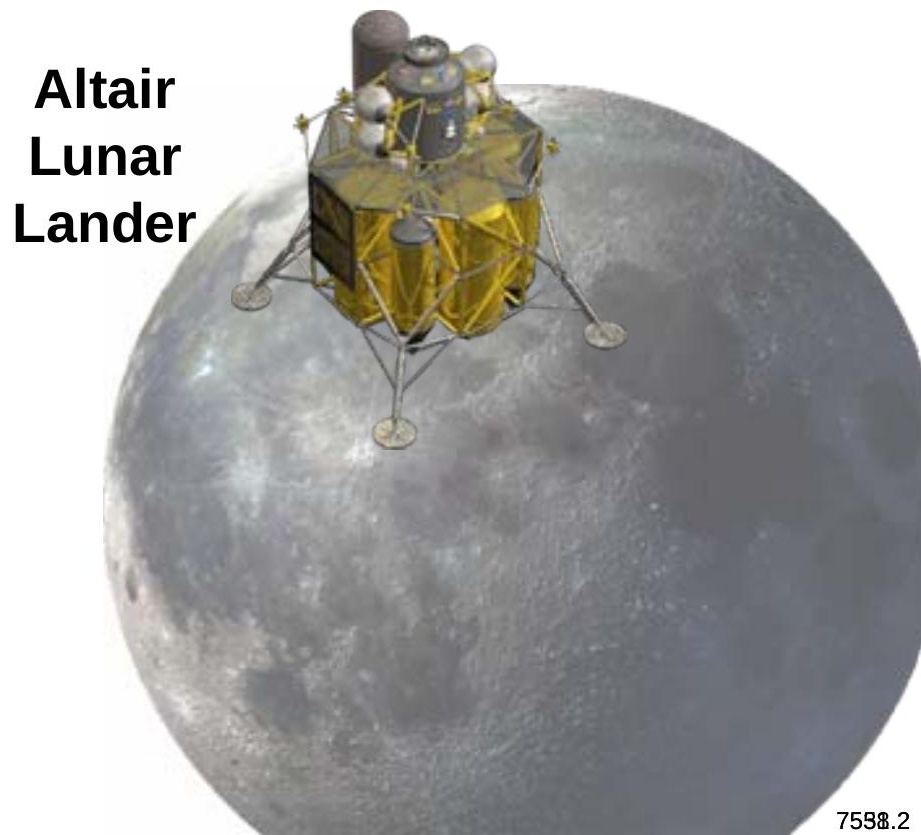




\section{The Ares Dual Launch Architecture}

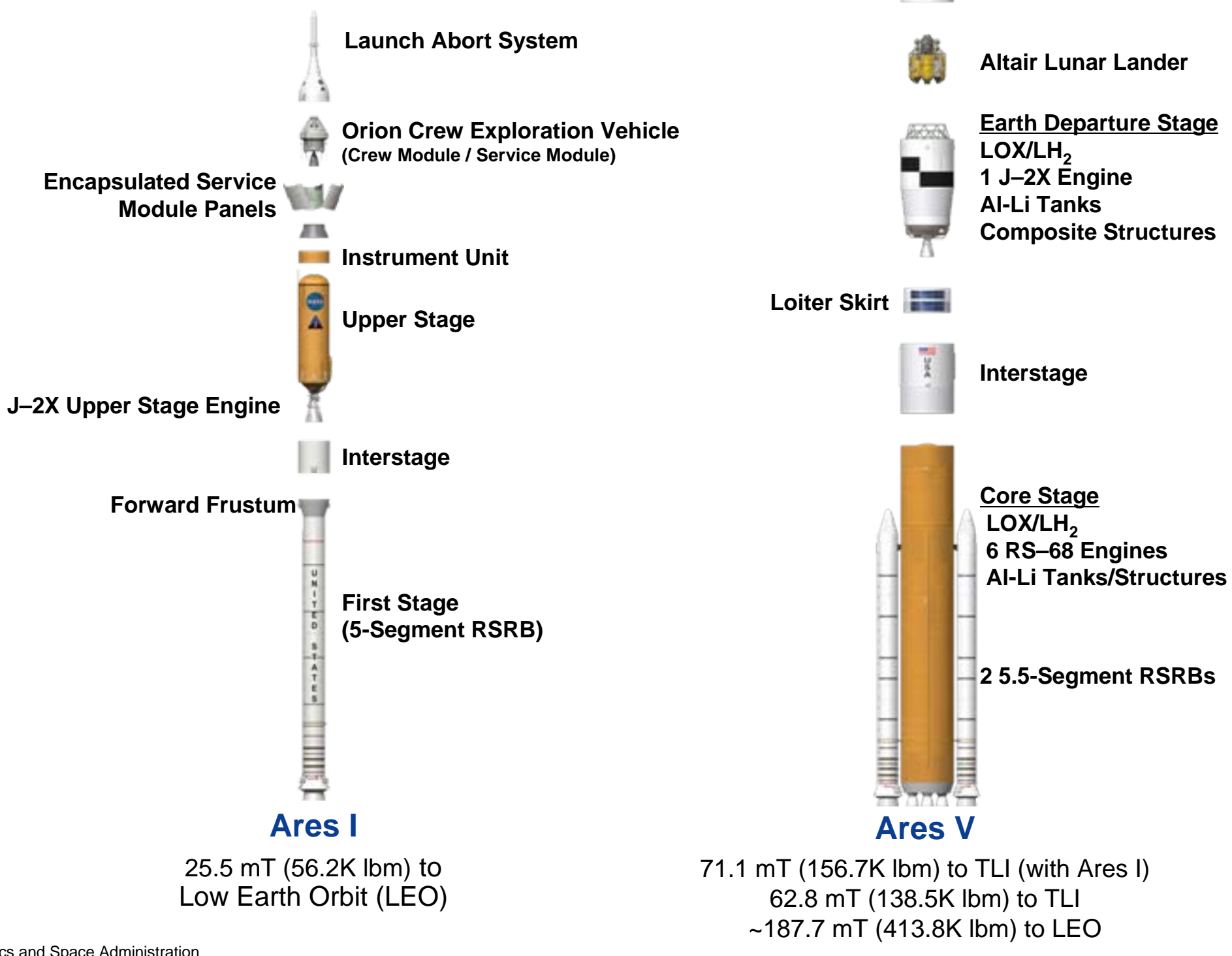

Composite Shroud

LOXILH $_{2}$

$1 \mathrm{~J}-2 \mathrm{X}$ Engine

Al-Li Tanks

Composite Structures

Loiter Skirt

$\mathrm{LOXILH}_{2}$

6 RS-68 Engines

Al-Li Tanks/Structures

First Stage

(5-Segment RSRB) 


\section{Building on a Foundation of Proven Technologies Launch Vehicle Comparisons}

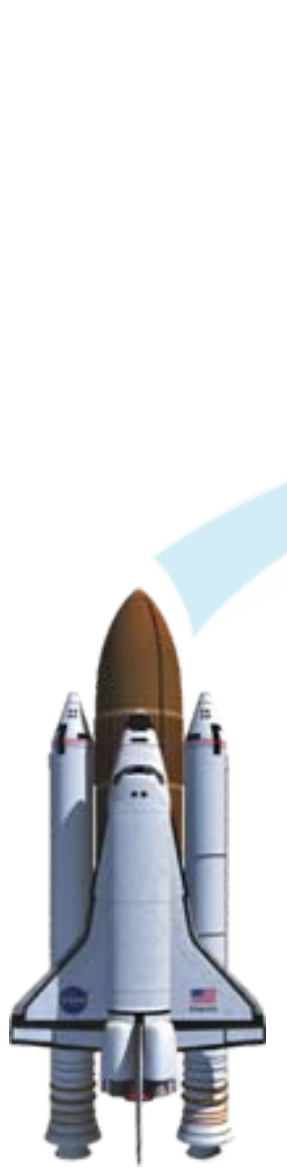

Space Shuttle

Height: 56 m (184 ft) Gross Liftoff Mass:

2,041.1 mT (4,500.0k lbm)

Payload Capability: $25.0 \mathrm{mT}$ (55.1k lbm) to Low Earth Orbit (LEO)

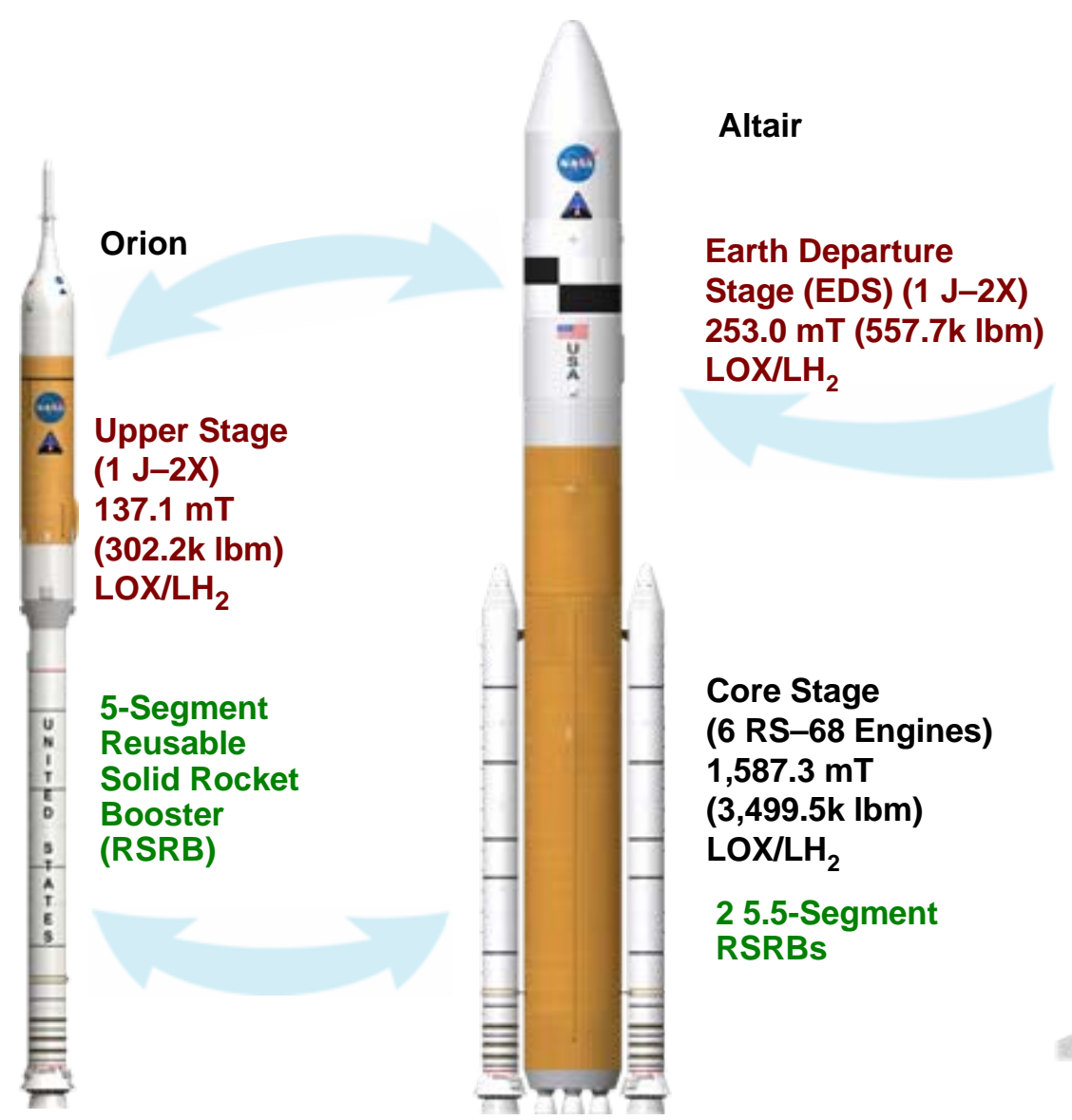

\section{Ares I}

Height: 99 m (325 ft) Gross Liftoff Mass: 927.1 mT (2,044.0k lbm) Payload Capability: $25.5 \mathrm{mT}(56.2 \mathrm{k} \mathrm{lbm})$ to LEO

\section{Ares V}

Height: $116 \mathrm{~m}(381 \mathrm{ft})$ Gross Liftoff Mass:

3,704.5 mT (8,167.1k lbm)

Payload Capability:

$71.1 \mathrm{mT}$ (156.7k lbm) to TLI (with Ares I)

$62.8 \mathrm{mT}(138.5 \mathrm{k} \mathrm{lbm})$ to TLI

-187.7 $\mathrm{mT}(413.8 \mathrm{k} \mathrm{lbm})$ to LEO
Crew

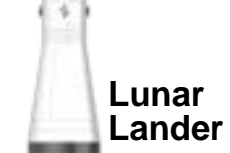

S-IVB

(1 J-2 engine) $108.9 \mathrm{mT}$ (240.0k lbm) $\mathrm{LOX}_{\mathrm{LH}} \mathrm{L}_{2}$

S-II

(5 J-2 engines) $453.6 \mathrm{mT}$ $(1,000.0 \mathrm{k} \mathrm{lbm})$ $\mathrm{LOXILH}_{2}$ S-IC (5 F-1) $1,769.0 \mathrm{mT}$ (3,900.0k lbm) LOX/RP-1 


\section{Review Milestones}

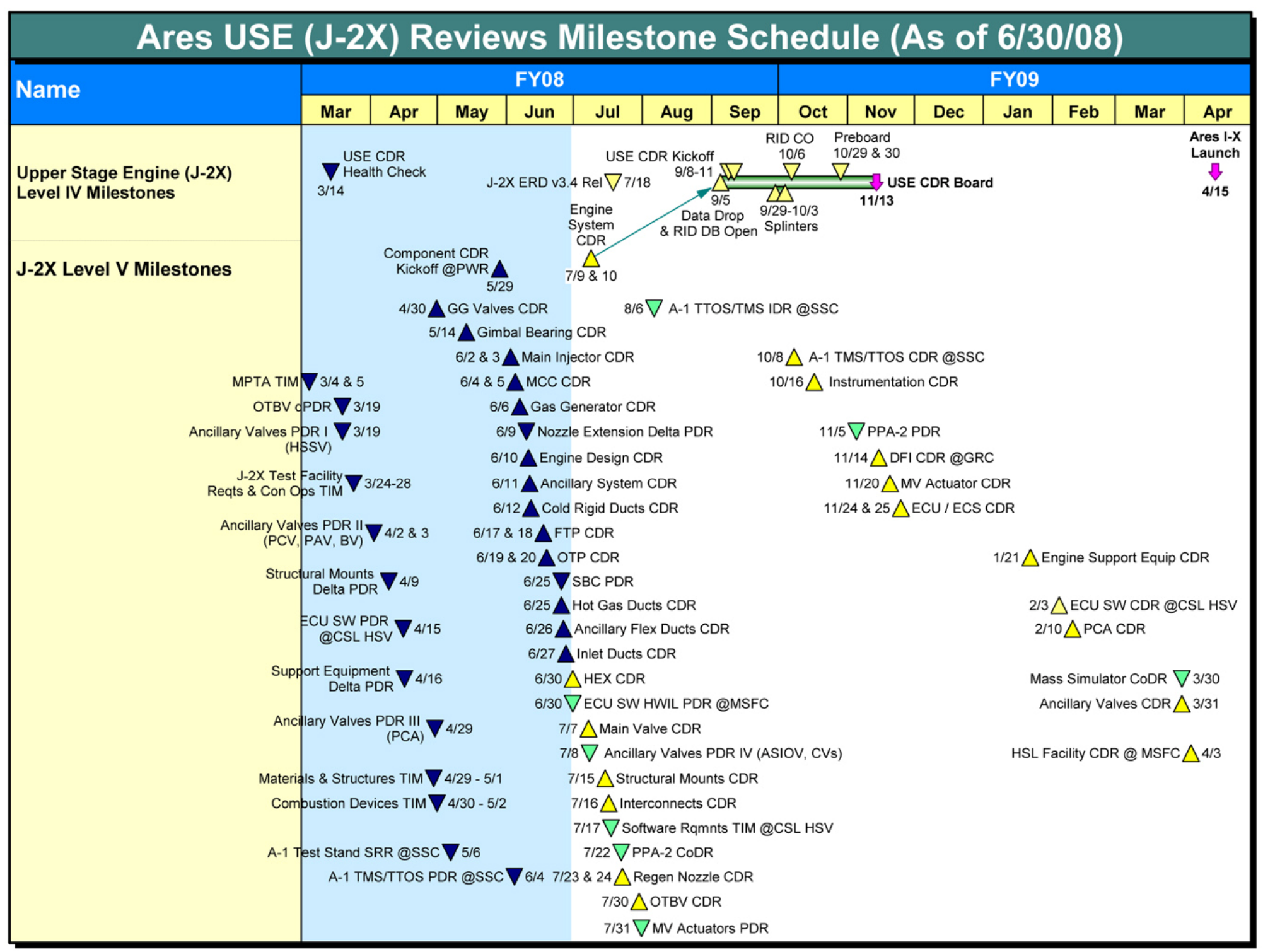




\section{Upper Stage Engine Key Requirements and Design Drivers}

Nominal Vacuum Thrust

- Nominal $=294,000$ lbs

- Open-loop control

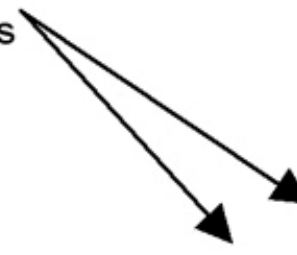

Mixture Ratio

- Nominal $=5.5$

- Open-loop control
Operational Life $=4$ starts and 2,000 seconds (post-delivery)

Engine Gimbal

- 4-degree square

- drives design of flexible inlet ducts and gimbal block

Health and Status Monitoring and Reporting

Data Collection for Post-Flight Analysis Engine Failure Notification

- drives towards controller versus sequencer

- drives software development and Validation and Verification (V\&V)

- Thrust $=\sim 82 \%$

- $\mathrm{MR}=4.5$

- Vacuum Thrust 242,000 lbs

Natural and Induced Environments

- first-stage loads on Ares I

- in-space environments for Ares $\mathrm{V}$
- Start at $>100,000$ feet (ft.)

- Second start after 5 days on orbit Secondary Mode Operation
- Minimum Vacuum Isp = $448 \mathbf{~ s e c}$

- drives size of nozzle extension

- drives increased need for altitude simulation test facility

- Nozzle Area Ratio 92:1 


\section{The J-2X Heritage: Avoiding Clean-Sheet Design}

\section{Turbomachinery}

- Based on J-2S MK-29 design

- Beefed up to meet J-2X performance

- Altered to meet current NASA design standards

- Helium Spin Start

\section{Gas Generator}

- Based on RS-68 design

- Scaled to meet J-2X needs

- Pyrotechnic Igniter

\section{Engine Controller}

- Based on RS-68 design and software architecture

Tube-Wall RegenerativelyCooled Nozzle Section

- Based on J-2/J-2S and long history of RS-27 success (Delta II/III)

\section{Heat Exchanger}

- Based on J-2 experience on Saturn S-IVB Stage

\section{Gimbal Block}

- Based on J-2 \& J-2S design

- Potential upgrade to more modern, demonstrated materials

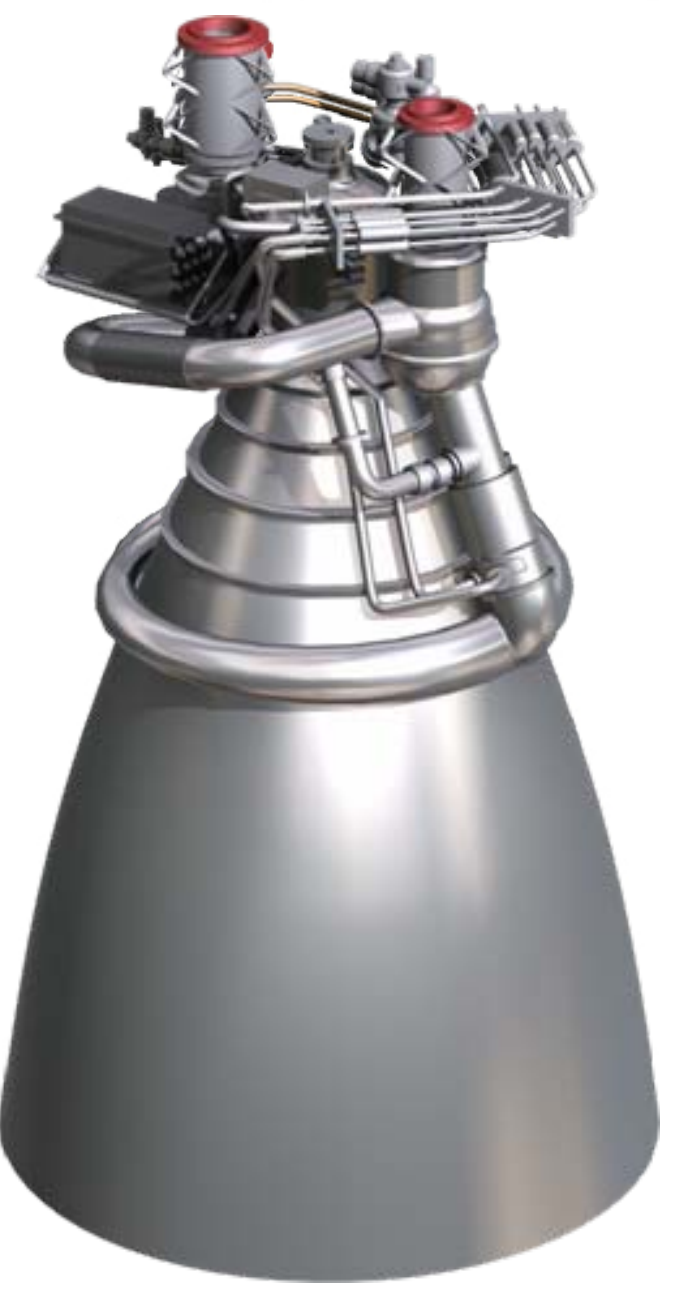

\section{Flexible Inlet Ducts}

- Based on J-2 \& J-2S ducts

- Adjusted to meet J-2X performance

- Altered to meet current NASA design standards

\section{Open Loop Pneumatic Control Valves \\ - Similar to J-2 and J-2S design \\ - Sector ball design traceable to XRS-2200 and RS-68}

\section{Main Injector}

- Based on RS-68 design to meet Isp

- Augmented Spark Igniter

\section{HIP-bonded Main Combustion} Chamber

- Based on RS-68 demonstrated technology

\section{Metallic Nozzle Extension}

- New Design 


\section{Test Facilities To Support J-2X Development}
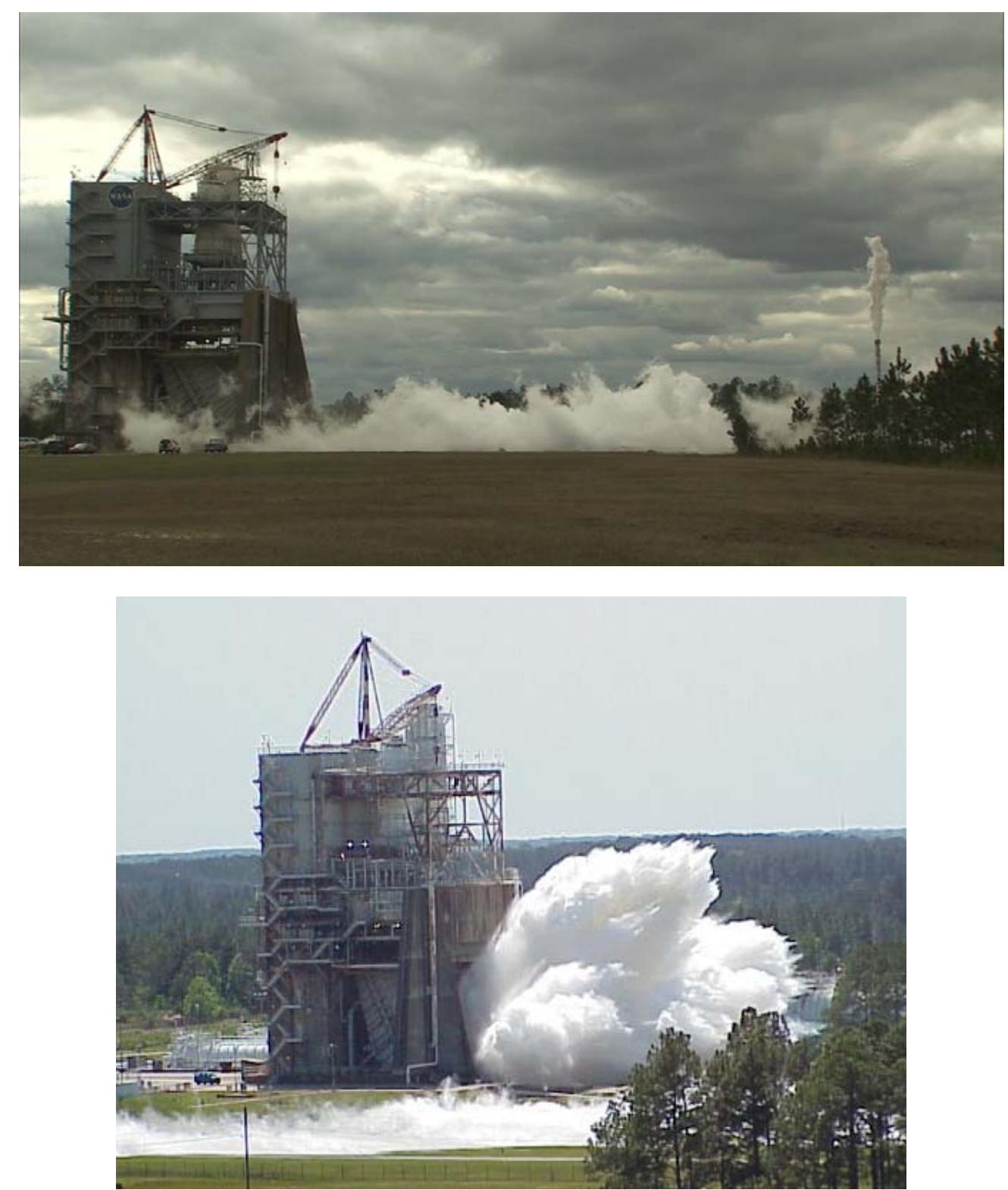

- SSC Test Stand A-1

- Powerpack testing

- Engine systems development testing

- Transferred from SSME to J-2X November 2006

- Refurbished in 2007

- Powerpack IA testing completed in 2008

- SSC Test Stand A-2

- Development and certification engine testing

- Pseudo-altitude testing with passive diffuser

- Engine performance verification

- Engine configuration - no nozzle ext \& stubby ext

- No engine gimballing

- Engine "Acceptance Series" type testing

- Transfer from SSME to J-2X in July 2009/Testing begins April 2010 


\section{Test Facilities (con't)}

\section{- SSC A-3 Test Stand}

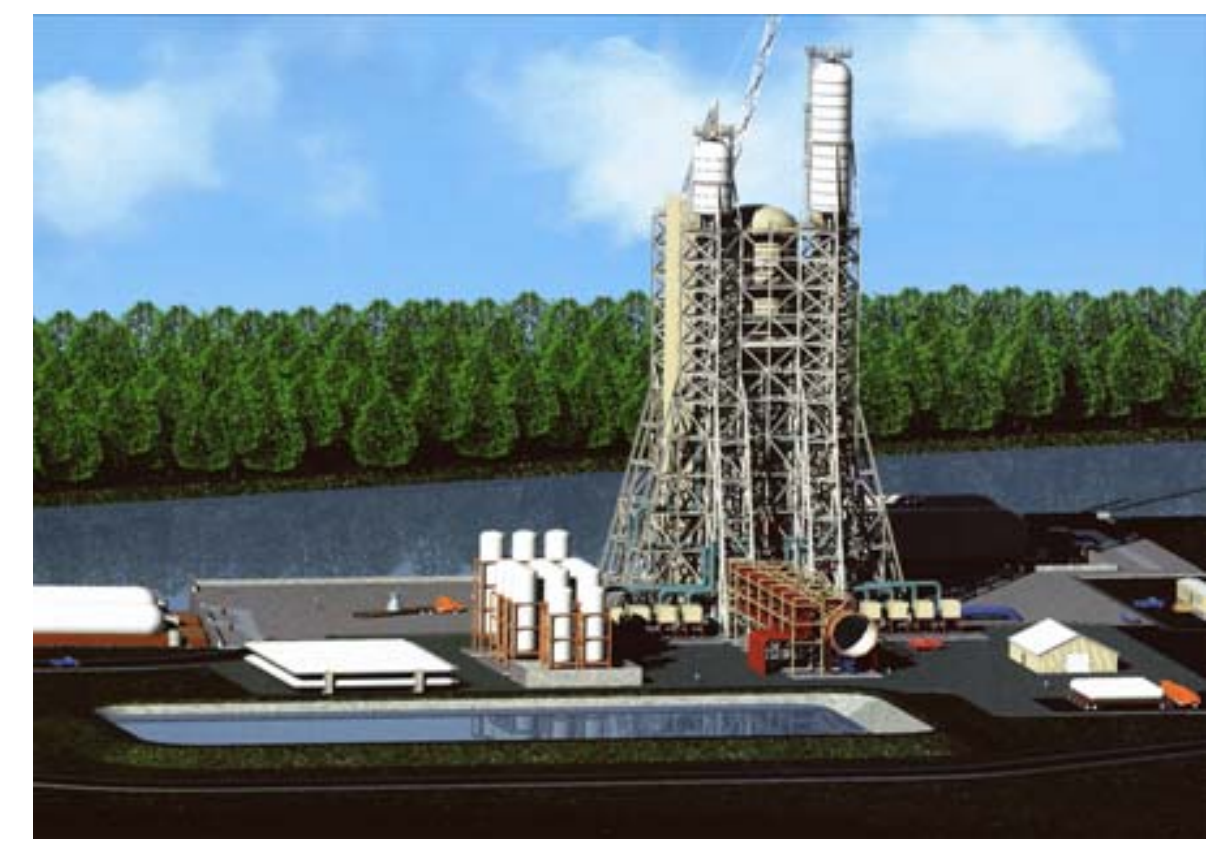

- Development and certification engine testing

- Performance at simulated altitude $(80,000 \mathrm{ft}-100,000 \mathrm{ft})$

- Engine configuration - no nozzle ext, stubby extension, and full nozzle extension

- Nozzle extension development and certification (4 units)

- Engine gimballing

- Engine Performance verification

- Vertical position hot-fire testing

- May 2007 Authority to Proceed

- Fall 2008 structural steel erected

- June 2010 Ready to Test 


\section{A-3 Construction Progress}

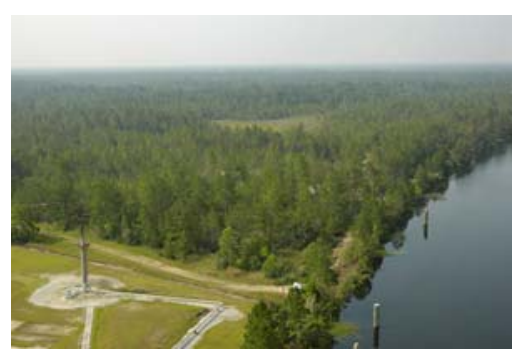

May 2007

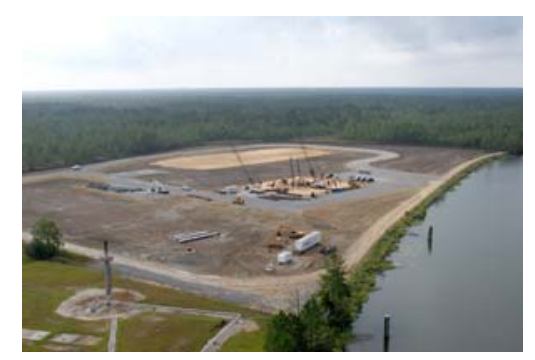

September 2007

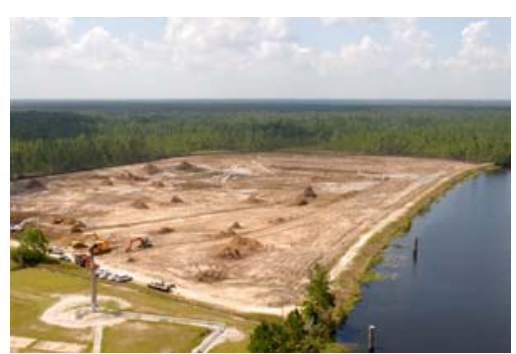

June 2007

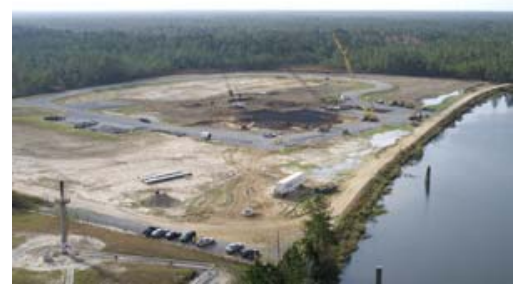

October 2007

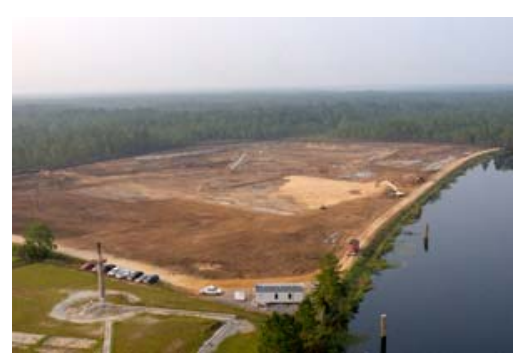

July 2007

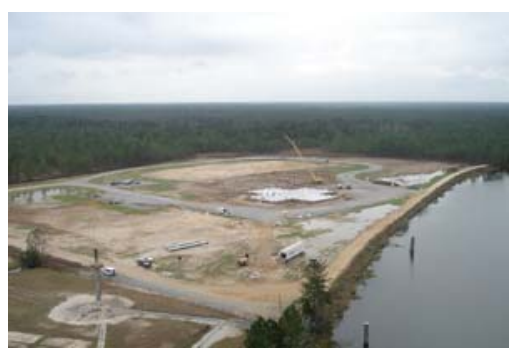

November 2007

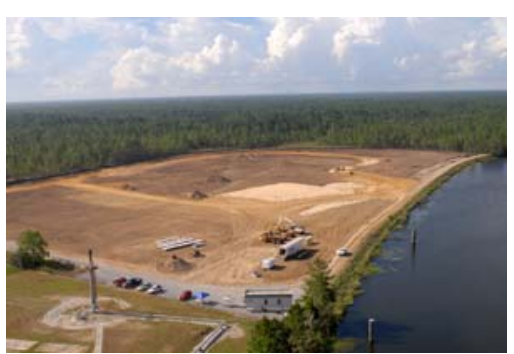

August 2007

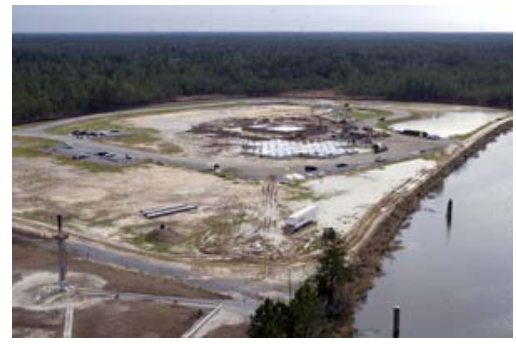

December 2007

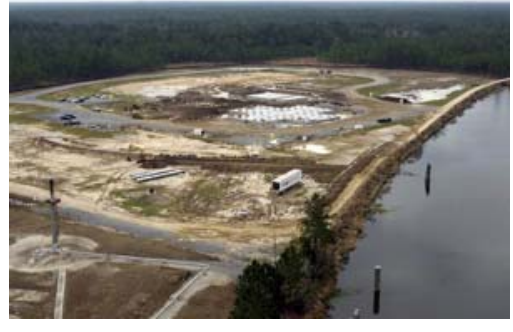

January 2008

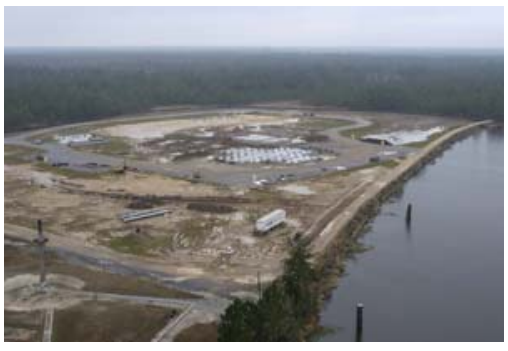

February 2008

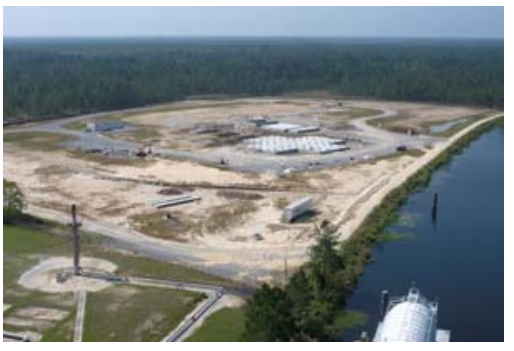

March 2008 


\section{A-3 Test Stand Construction}

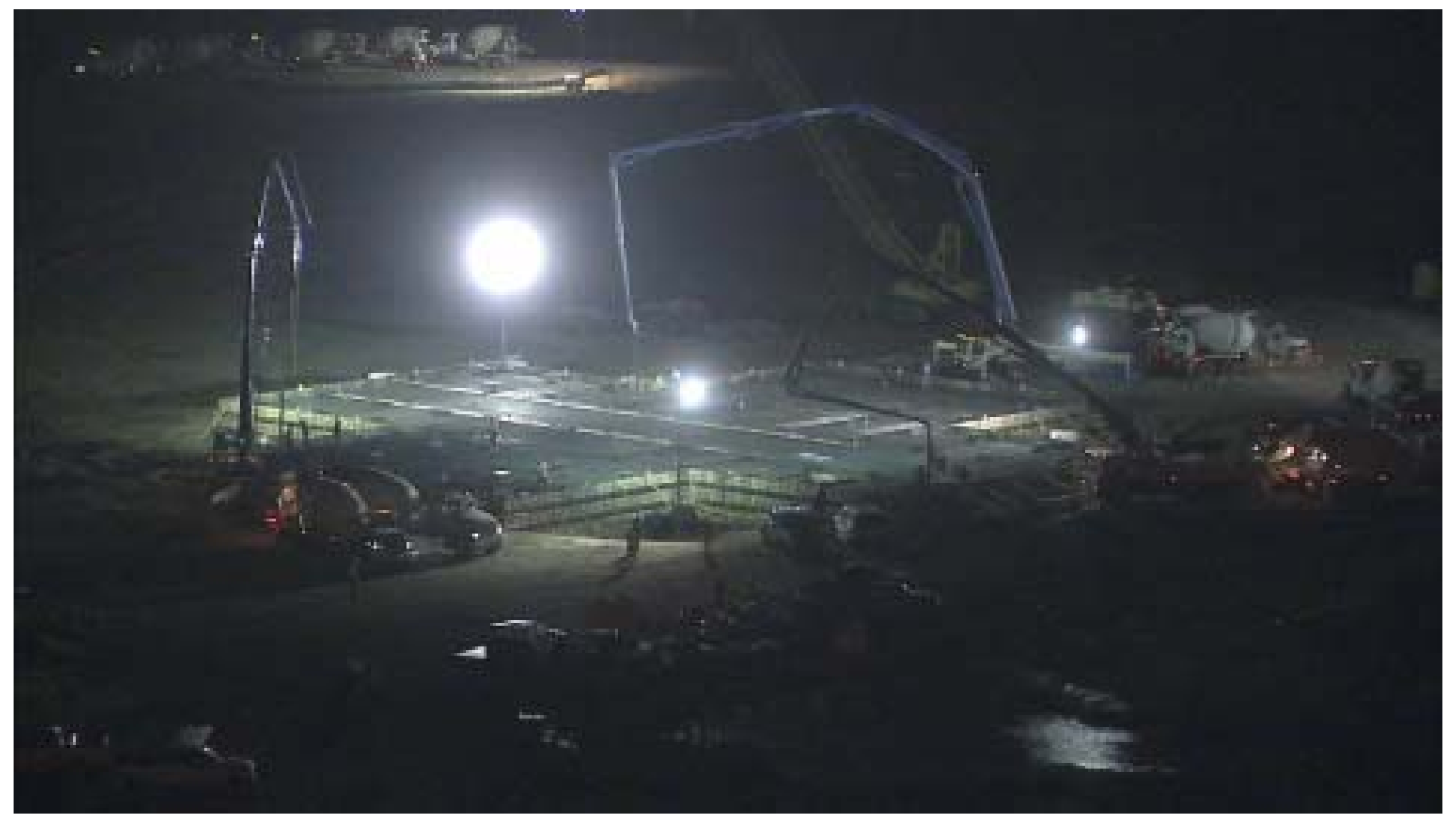




\section{Subscale Diffuser Testing for the A-3 Test Stand}

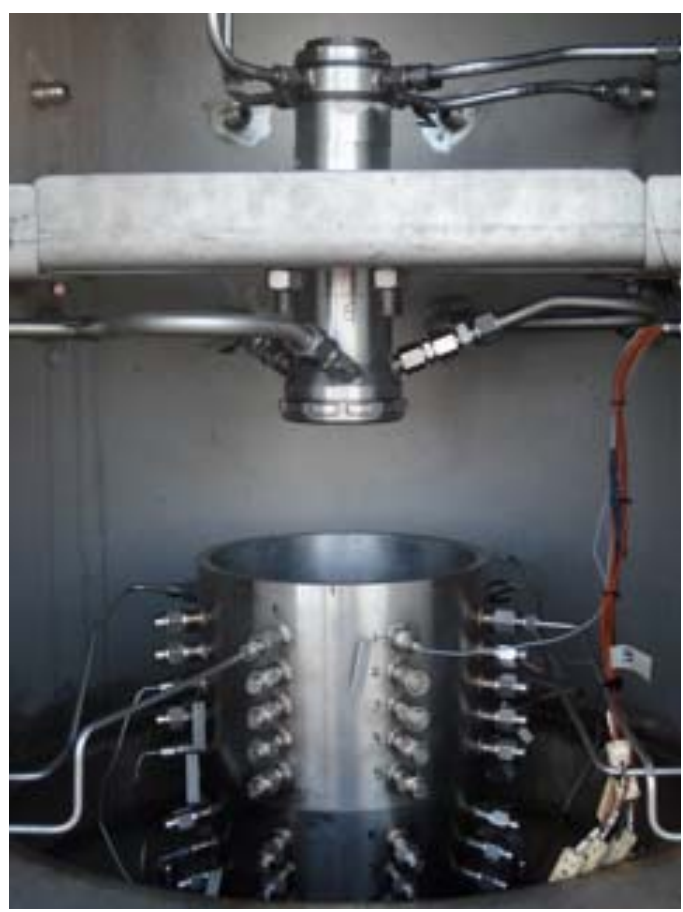

Subscale Diffuser test cell and rocket motor

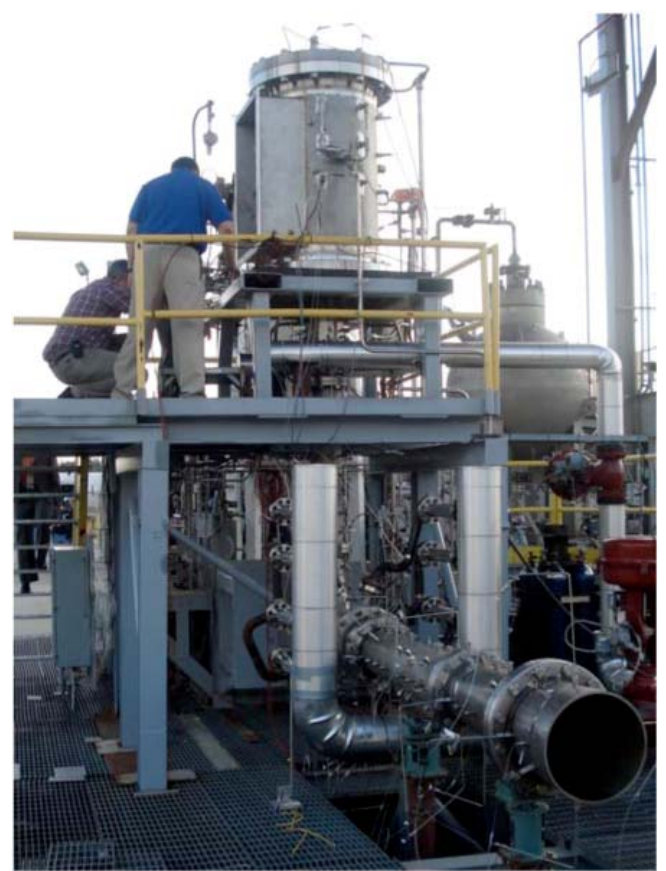

Subscale Diffuser test article

- $6 \%$ scale functional model to test diffuser and steam ejector design prior to full scale construction

- Successful demonstration in January - May 2008

- Supported design data for full-scale diffuser bid package and first stage ejector configuration 


\section{Subscale Diffuser Testing}

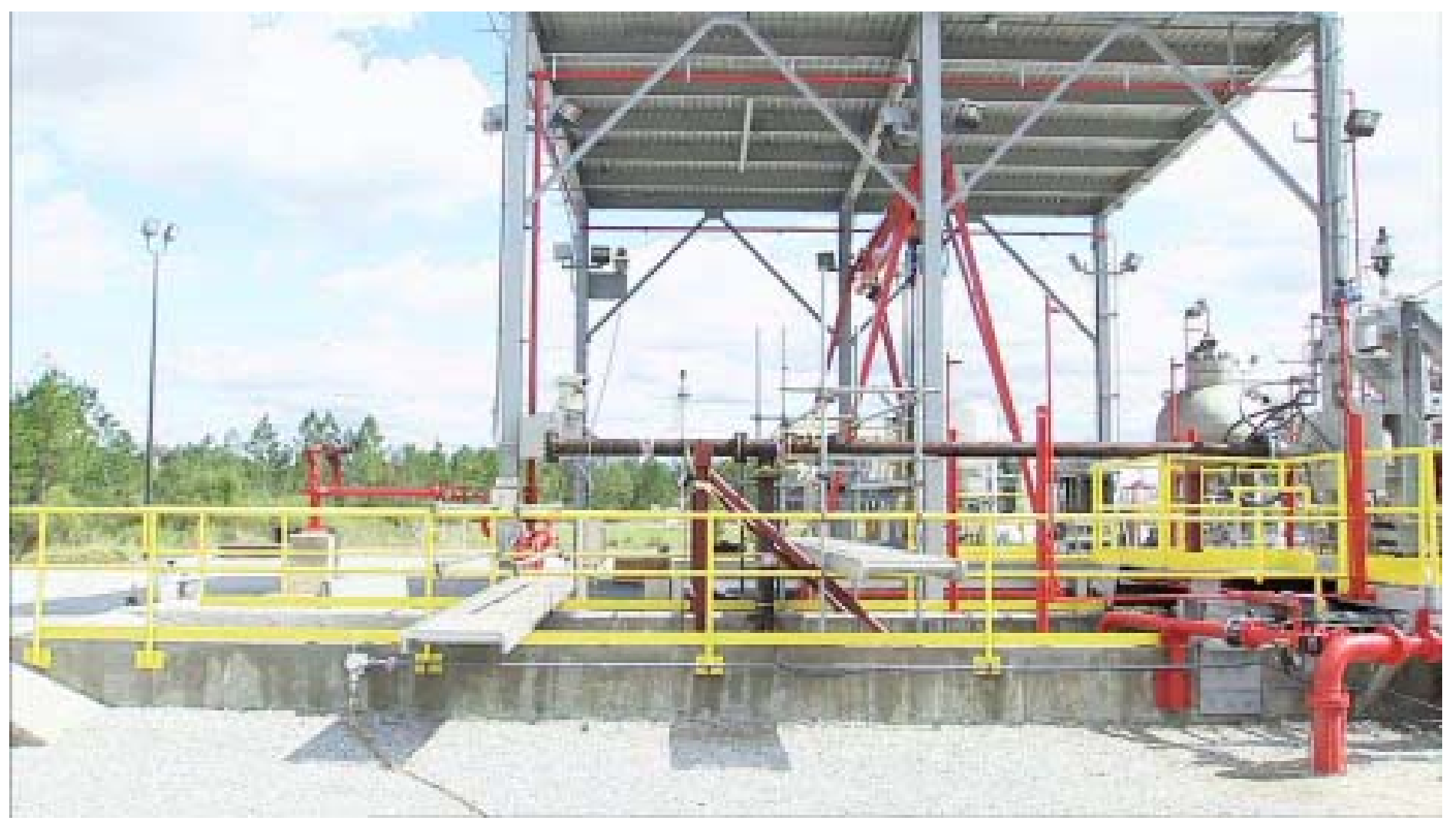




\section{Informing the Design via Early Component Testing}

Main Injector Tests

-J-2X DDT\&E

-ISubscale

FTP Inducer Tests

-Heritage and J-2X DDT\&E

-Subscale

FTP Turbine Air Flow Tests

-J-2X DDT\&E

-Full Scale

Work Horse Gas Generator

-J-2X DDT\&E

-Full Scale

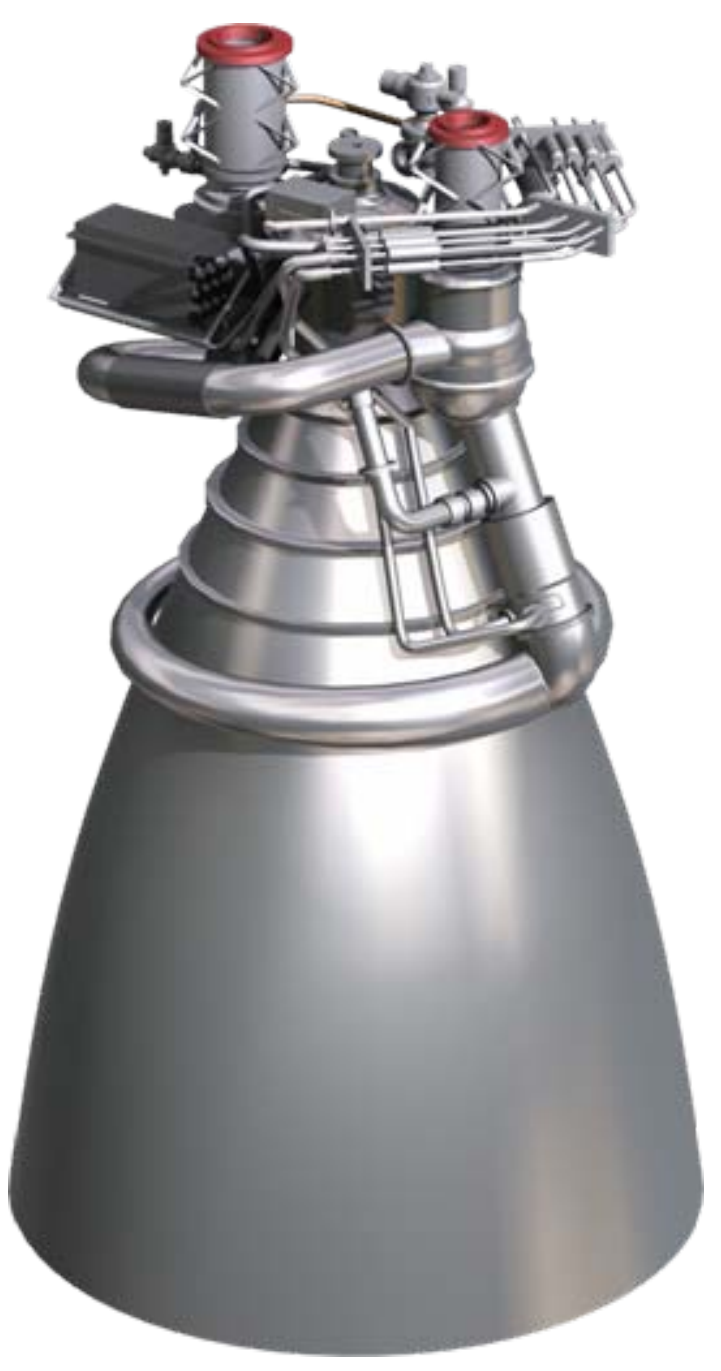

\section{Powerpack Tests}

-Heritage fuel and oxidizer turbopumps, gas generator, heat exchanger, spark igniters, helium spin start

-Full Scale

\section{OTP Inducer Tests}

-Heritage and J-2X DDT\&E

-Subscale

\section{Nozzle Side Loads Tests}

-Heritage and J-2X DDT\&E

-Subscale 


\section{Powerpack 1A Testing}

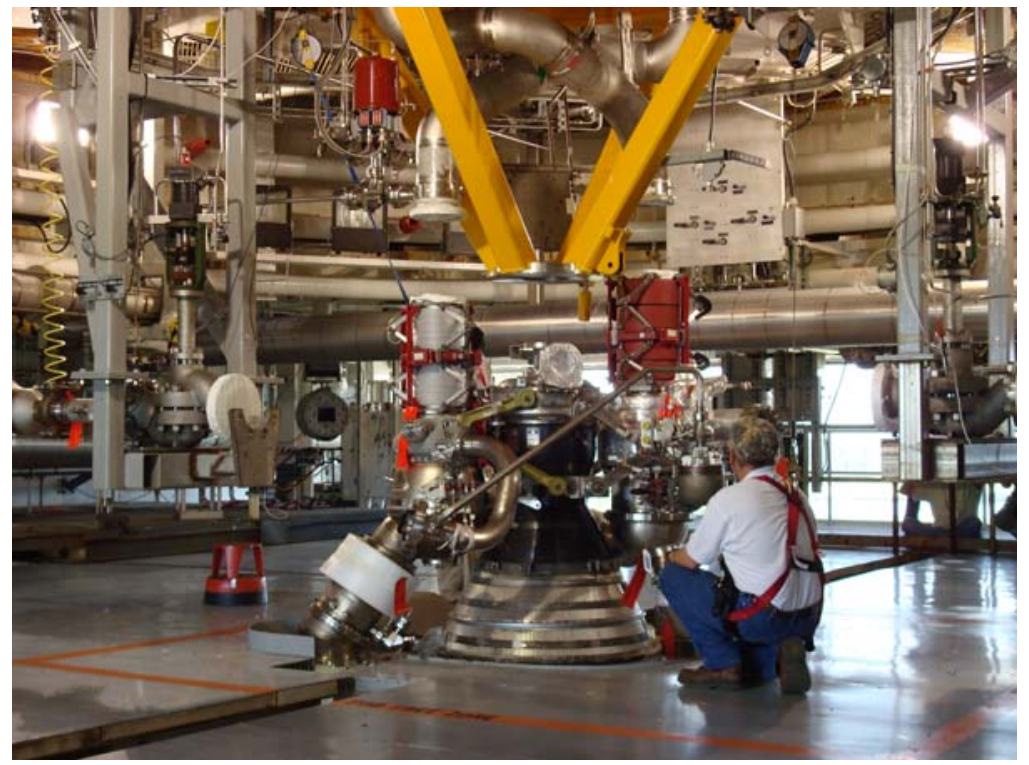

PPA-1A installation and checkout

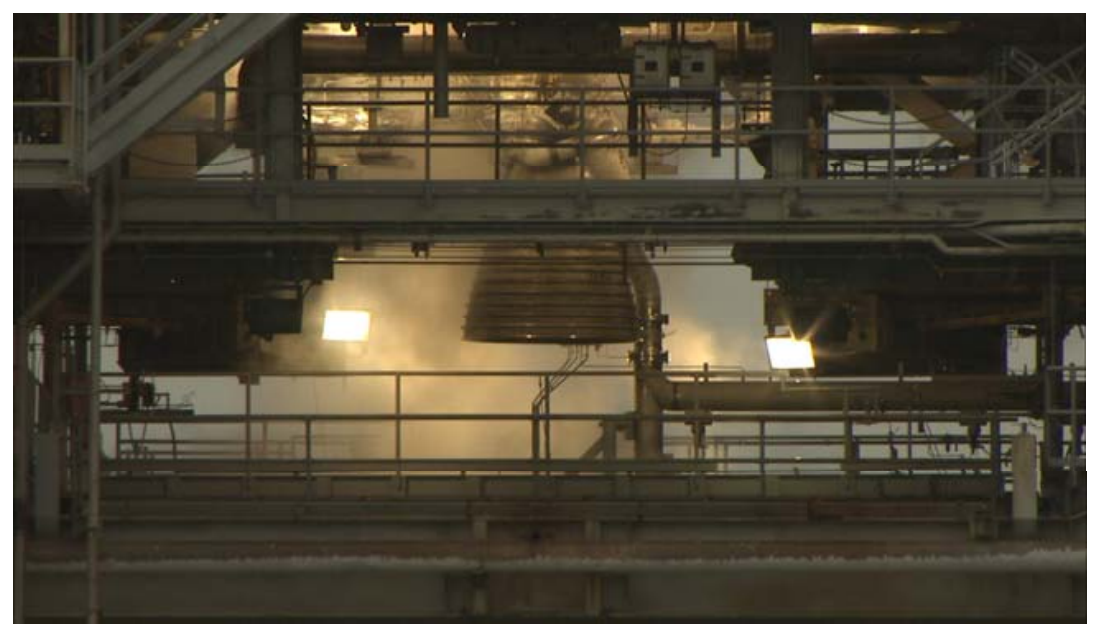

PPA-1A \#8
- Powerpack IA Hardware

- Heritage J-2S turbopumps from X-33

- Heritage J-2 propellant inlet scissor ducts

- Heritage J-2 gas generator, heat exchanger, spark igniters, helium spin start, and associated hardware from X-33

- Heritage J-2 crossover duct.

- Validate heritage turbomachinery and mitigate early design risk

\section{- Objectives}

- Obtain higher fidelity turbopump performance data

- Obtain inducer flow environments

- Identify HOSC/HORC

- Anchor and modify analytical approach

- Evaluate turbomachinery performance coupled to Ares MPS-like feedlines

- Determine OTP inducer compliance

- Measure turbopump cavitation induced vibration environments

- Validate MPS feedline and engine inlet duct CFD

- Correlate scissor duct response to HOSC/HORC

- Operate in $218 \mathrm{~K}$ to $274 \mathrm{~K}$ and 5.5 mixture ratio operating conditions

- Verify safe start and run operation at J-2X start and run boxes

- Evaluate empirical data vs. analyses and update models 


\section{Powerpack Testing}

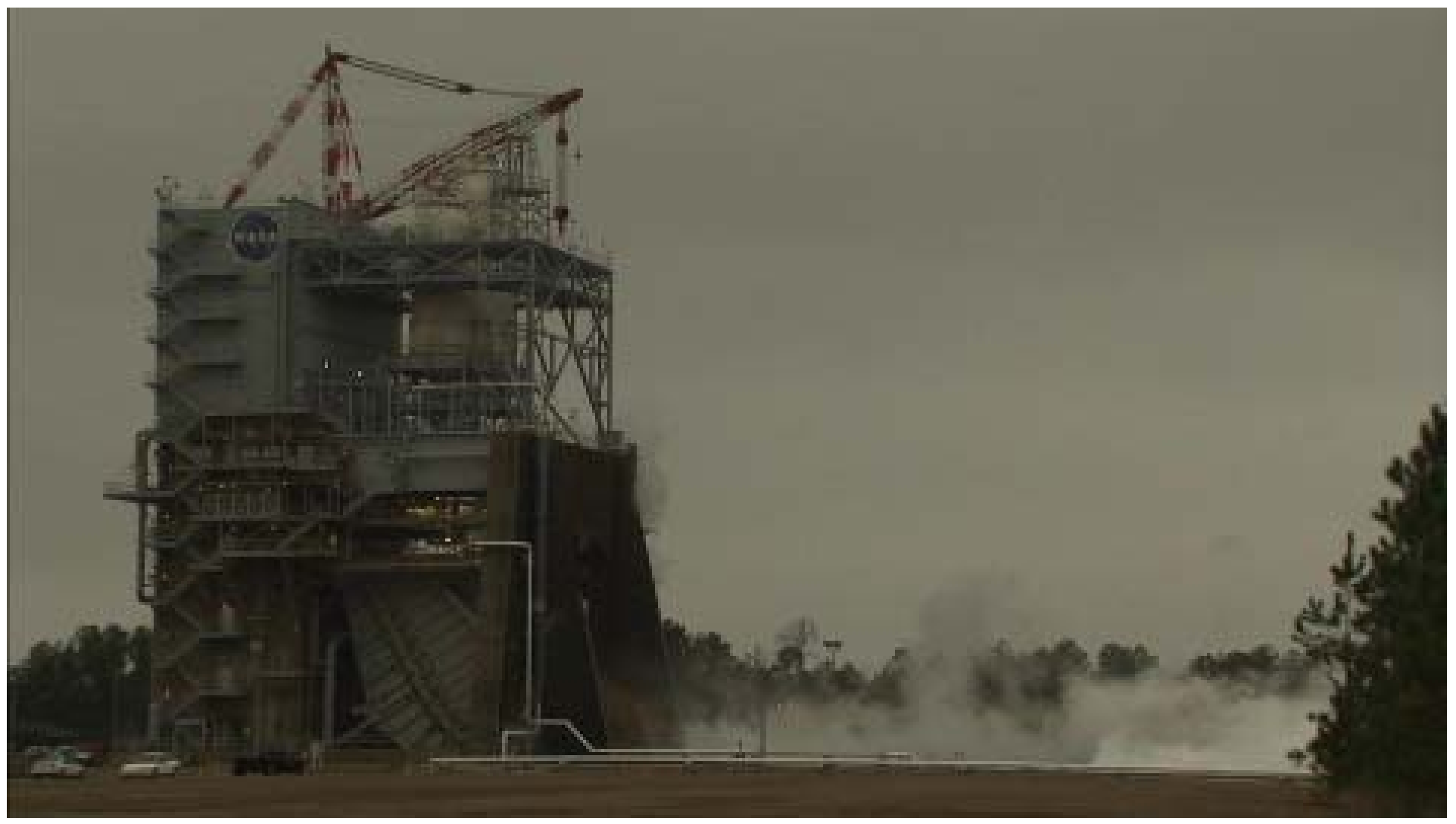




\section{Powerpack IA Results}

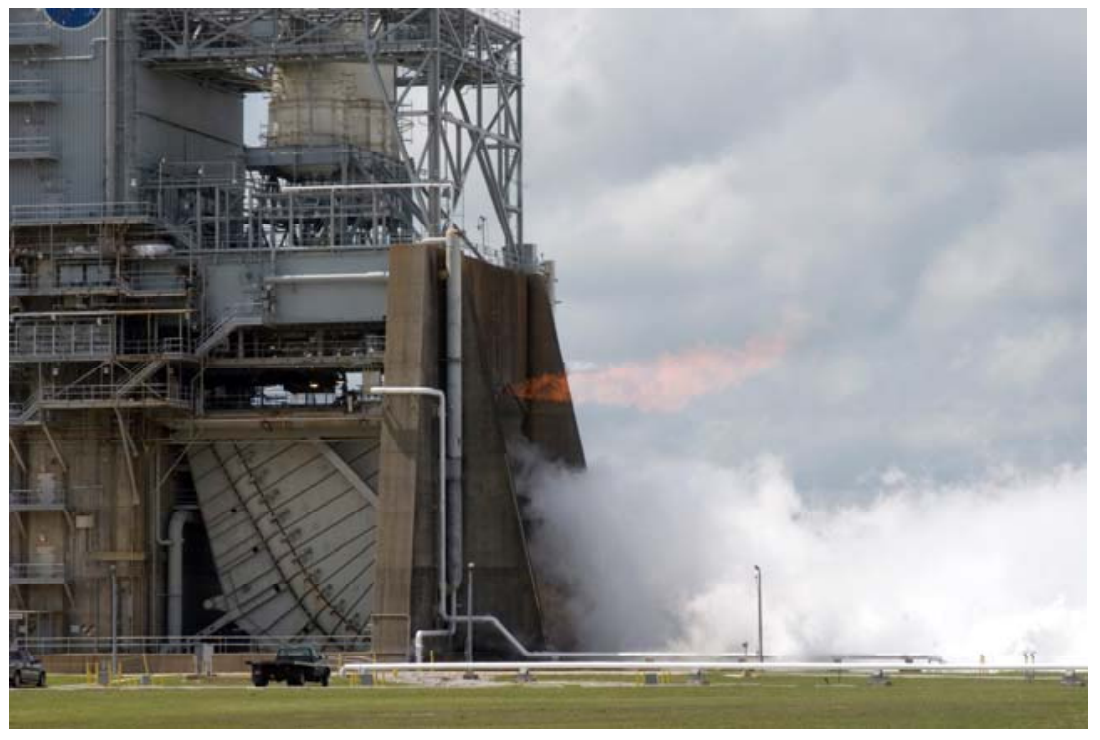

PPA-1A Hot-fire Test \#8

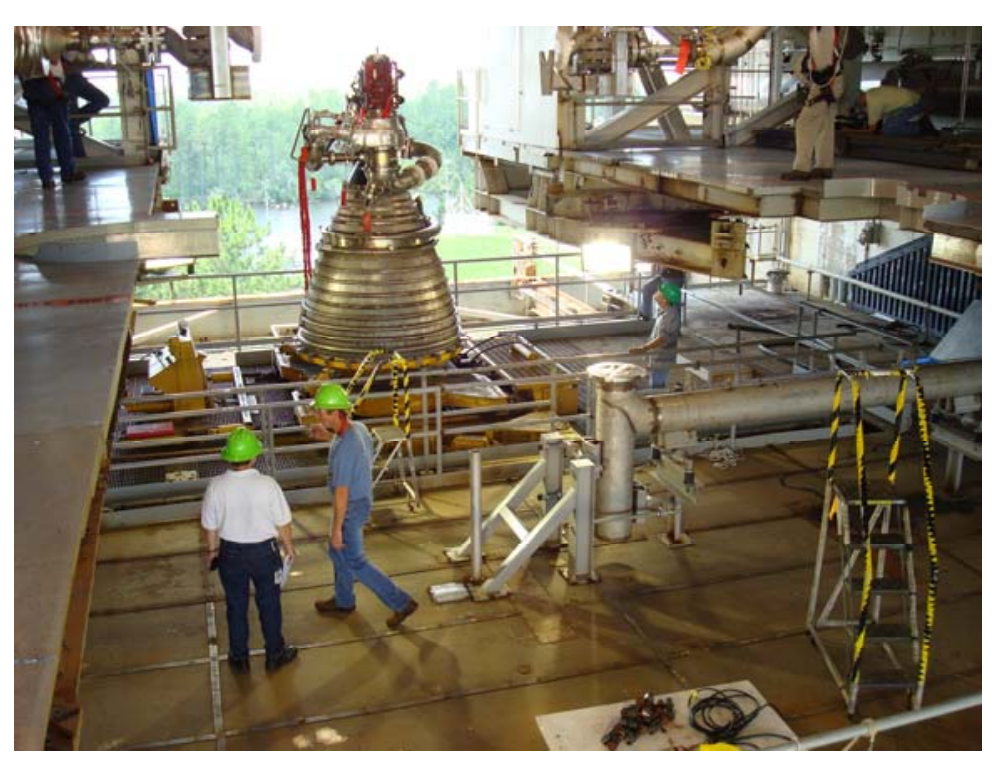

Powerpack test article removal from Test Stand A-1

- 6 "hot-fire" tests, Feb. 15 - May 8

- 1,343+ seconds operating time

- Power levels up to equivalent 274,000 pound thrust required for Ares I mission

- Resolved difference in heritage turbopump performance data and recent componentlevel tests

- Assessed potential "pogo" issues

- Investigated scissors duct performance

- Powerpack hardware disassembled for analysis

- Development J-2X powerpack scheduled for 2010 test series on A-2 stand 


\section{Subscale Injector Testing}

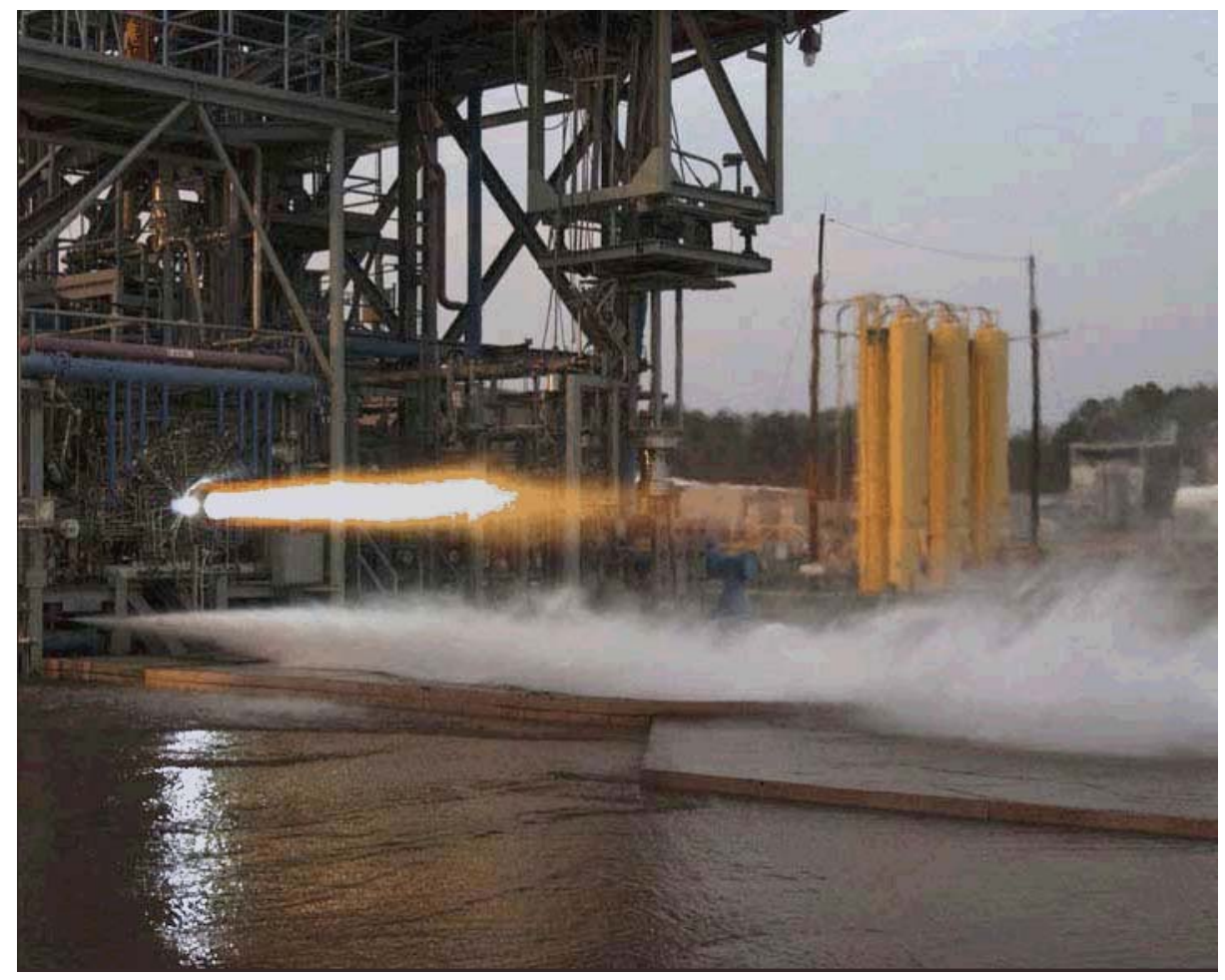

-52-Element Subscale Main Injector

- Represented full scale element density

$\checkmark 6$ Element Baffles corresponded to baffle/core element ratio of full scale design

- 15 hot-fire tests, 200+ seconds at main-stage

- Successfully validated engine performance analysis and main injector design selection 


\section{Subscale Injector Testing}

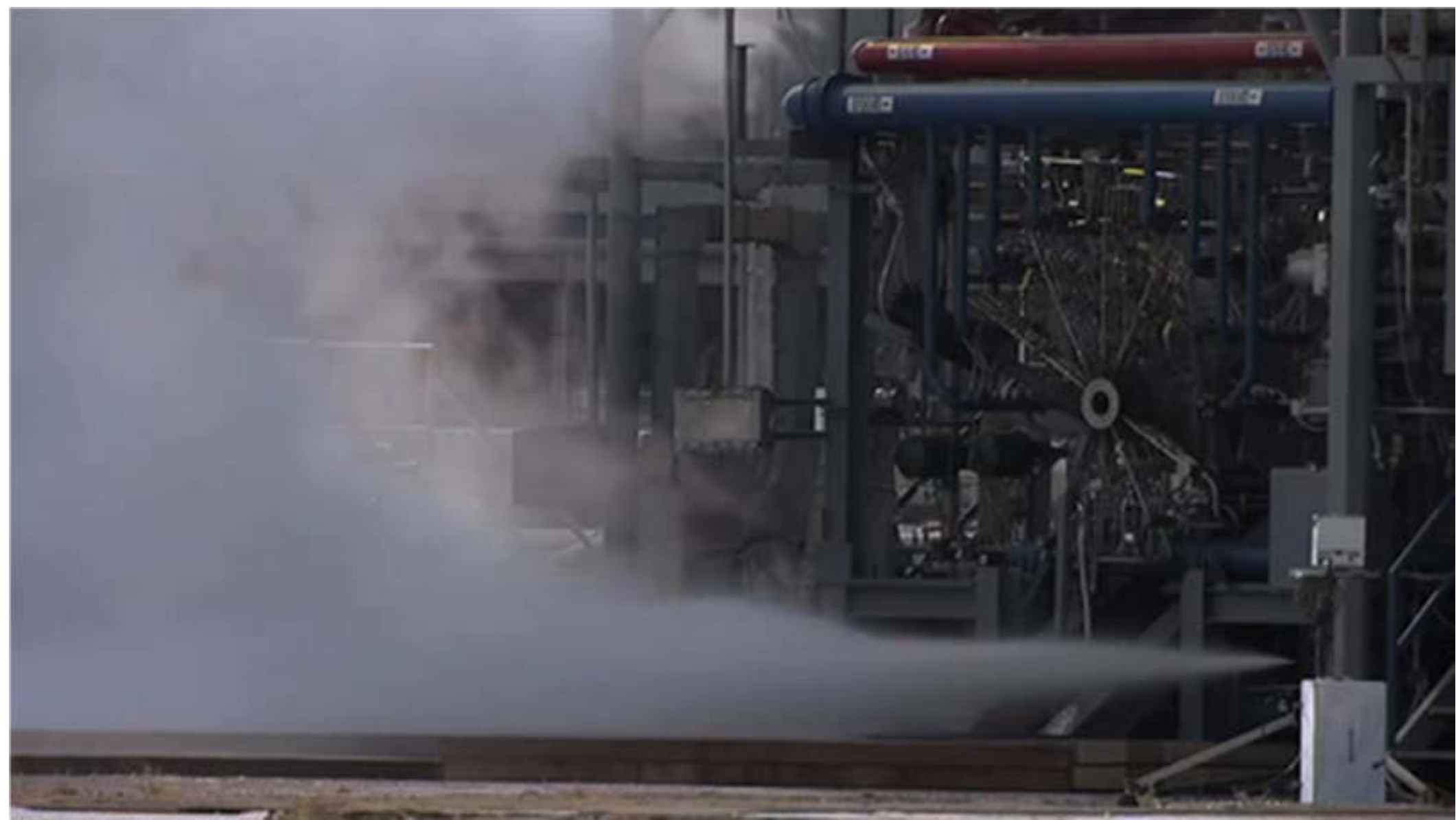




\section{Workhorse Gas Generator Testing}
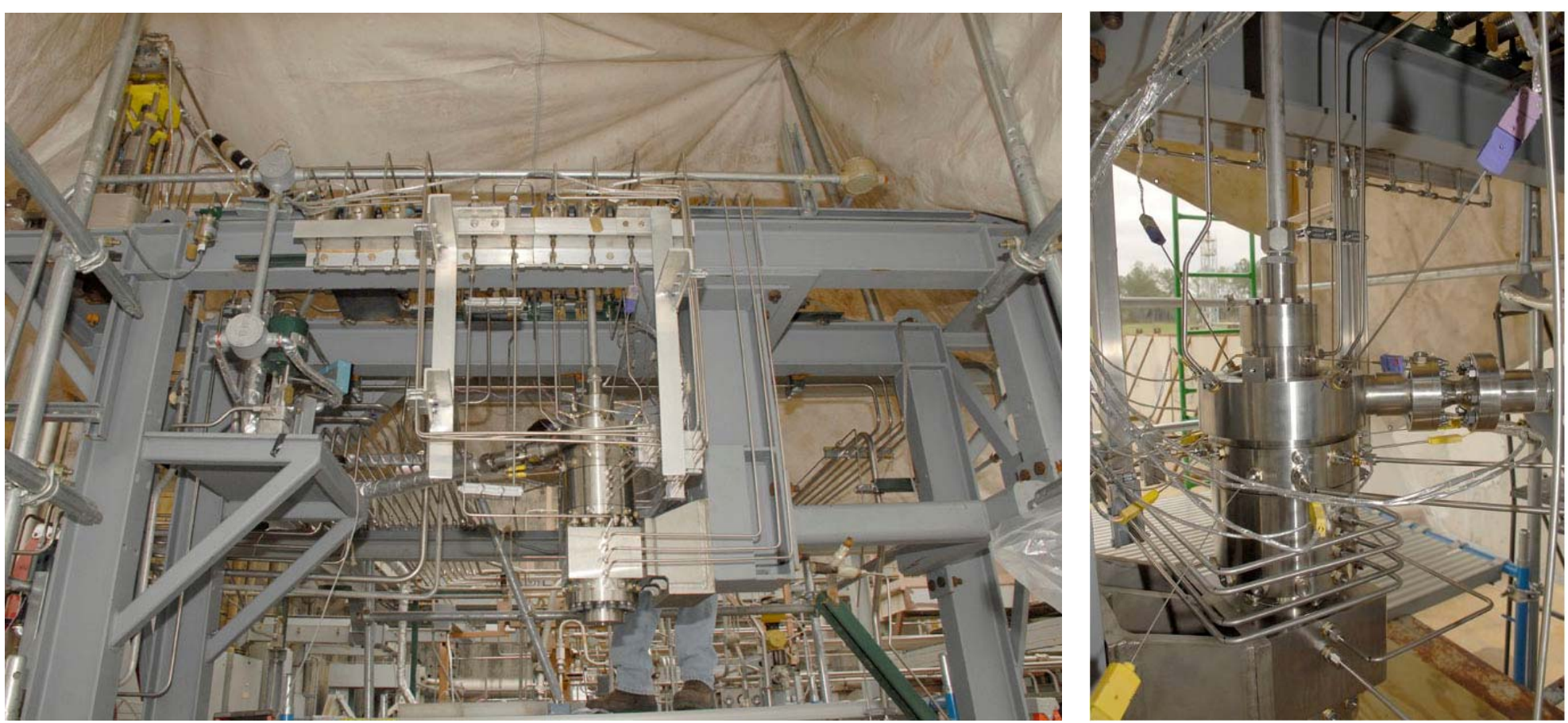

Workhorse Gas Generator test rig, left, and closeup of GG, right

- Designed to test J-2X gas generator configuration using non-flight-like hardware before committing to design

- Testing in phases beginning with GG and adding elbow, U-duct, and fuel turbine simulator

- 61- and 43-element injectors tested with straight and 90-degree configuration chambers

- Objectives include:

- Demonstration of pyro igniter, helium spin start, GG fuel- and oxidizer-side purge, injector face heating, injector/chamber compatibility, temperature uniformity of GG combustion products to FTP inlet flange and turbine nozzles, etc.

- Testing will result in downselect of GG chamber length and injector element pattern 


\section{Workhorse Gas Generator Test}

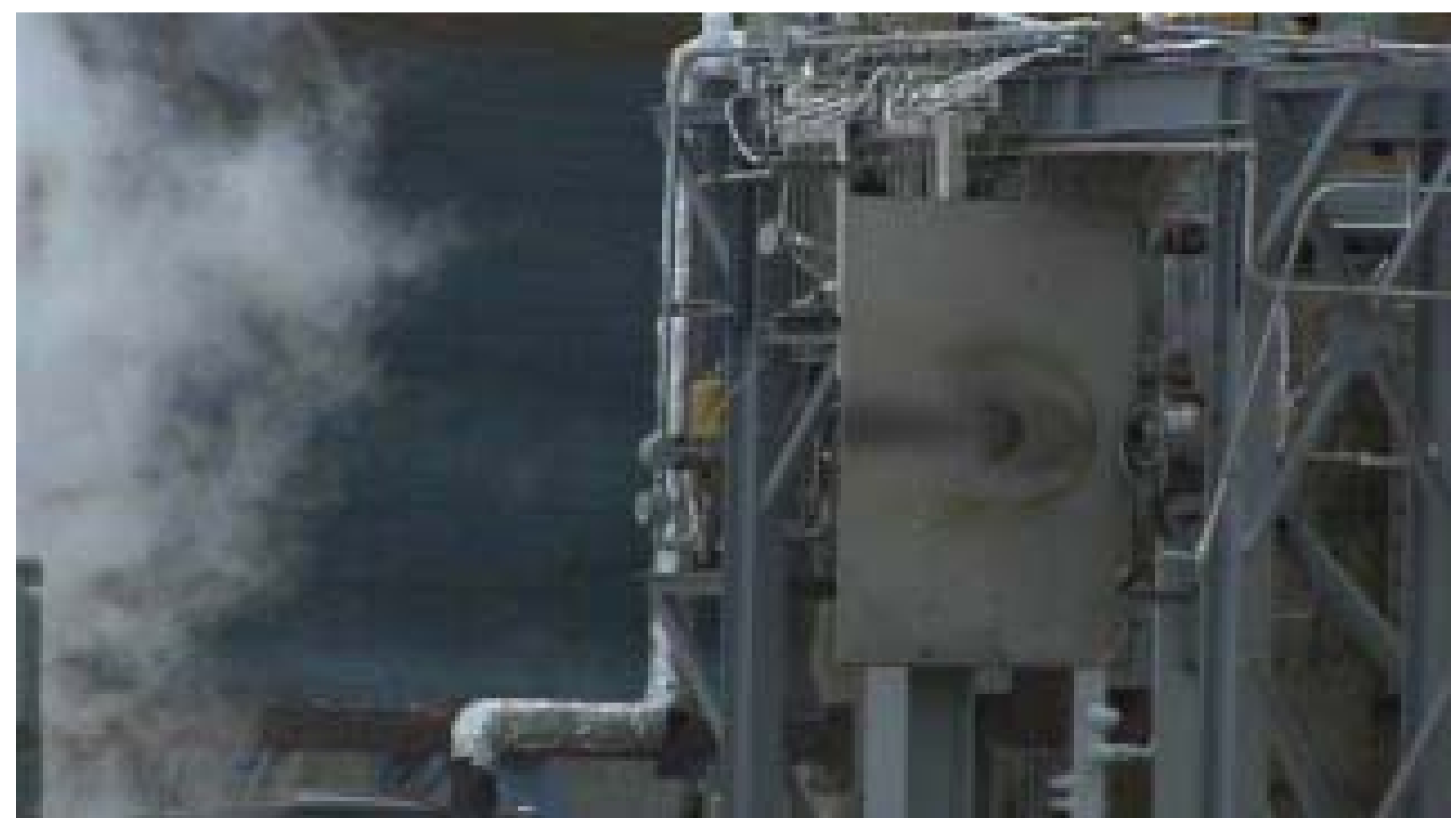




\section{Nozzle Side Loads Testing}
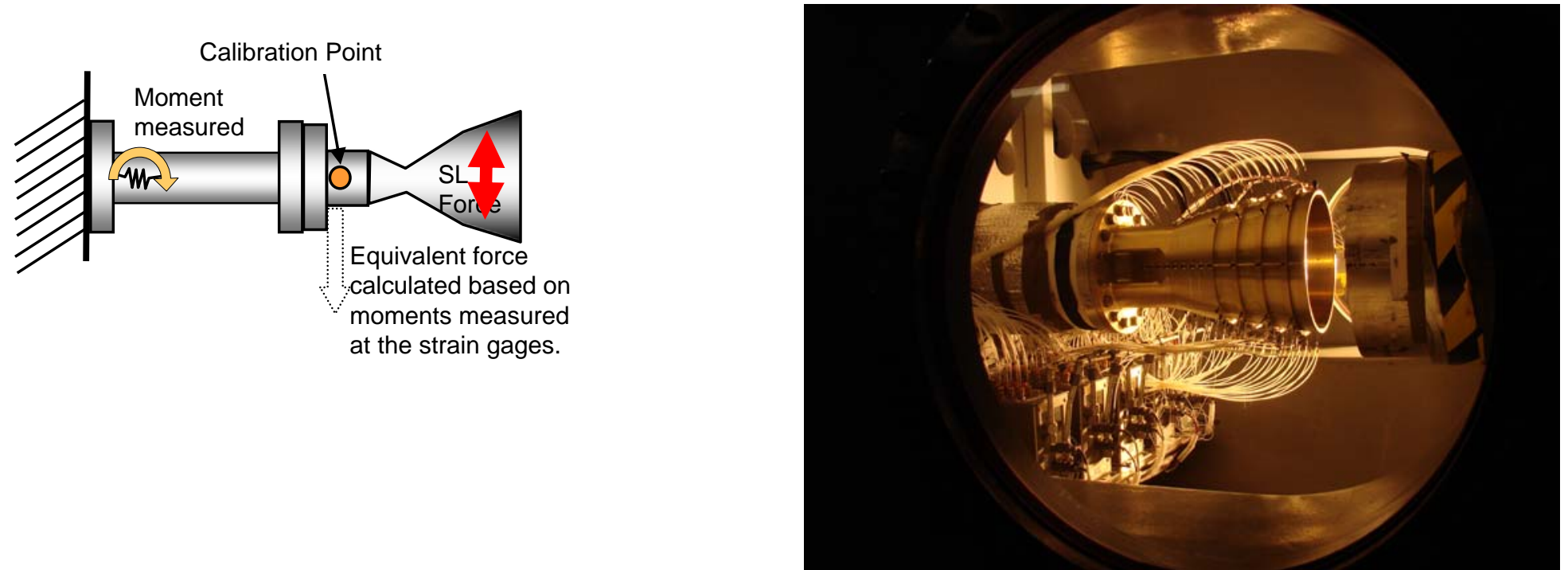

- Nozzle contour selection important due to nozzle extension requirement

- Truncated Ideal Contour (TIC) selected for J-2X

- Goal to optimize design with minimum side loading and maximum performance

- "Knock-down" factor of 21 percent established

- 2008 tests will investigate impact of turbine exhaust gas injection 


\section{SSME Sideloads}

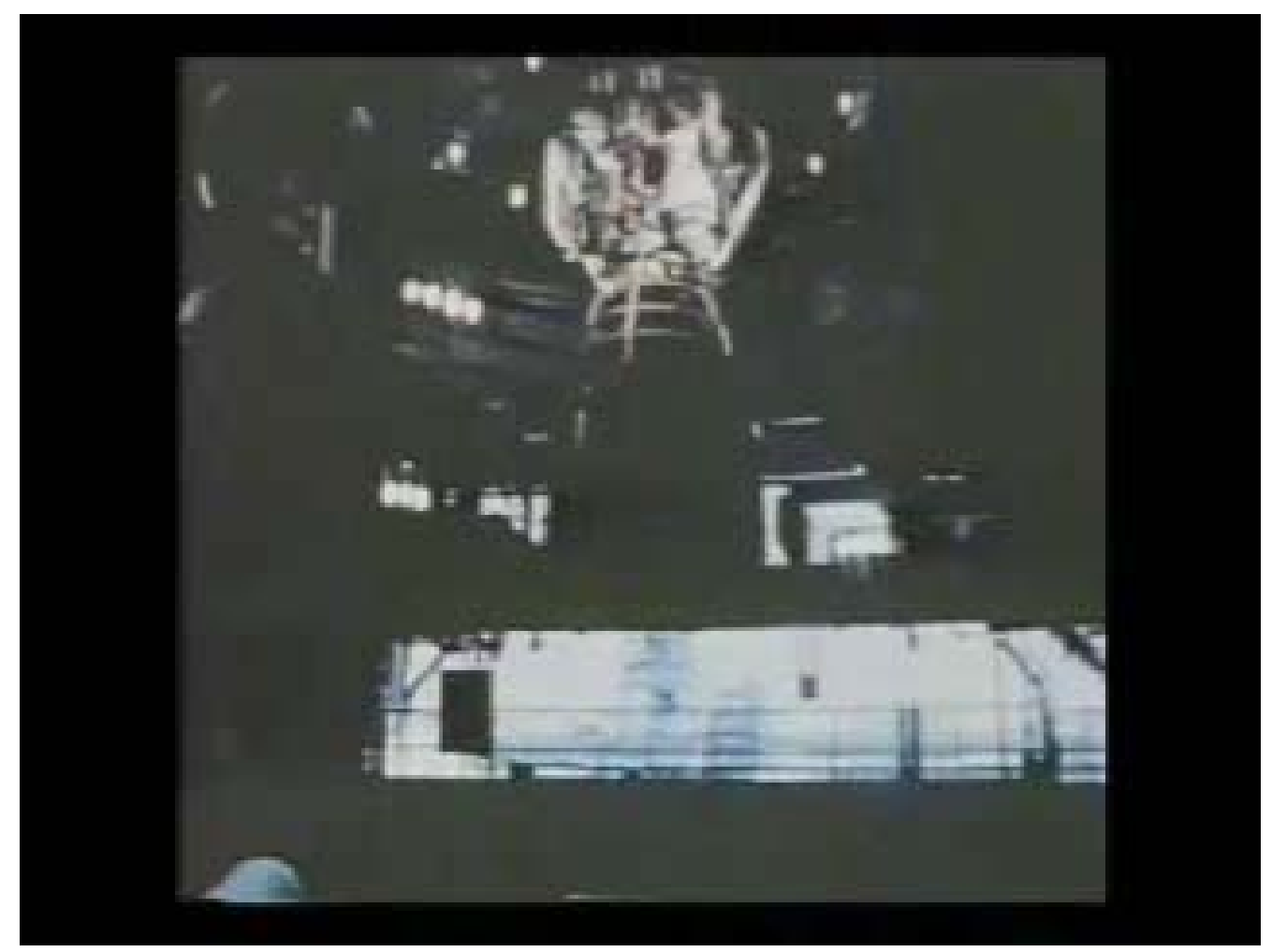




\section{LOX Turbopump Subscale Inducer Testing}

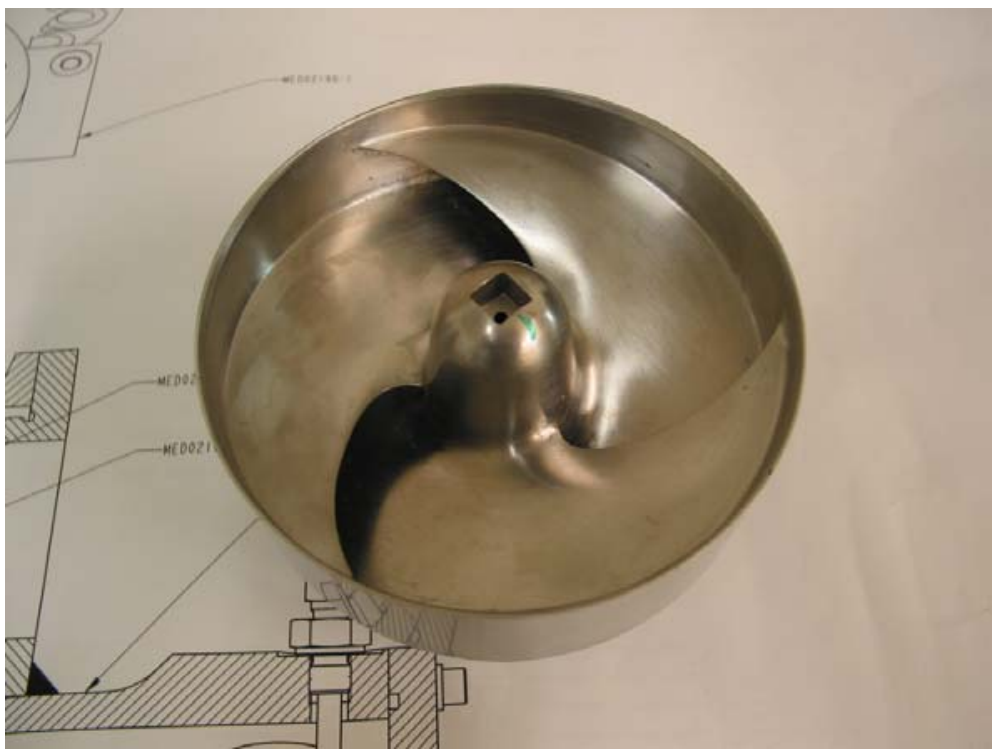

Subscale inducer

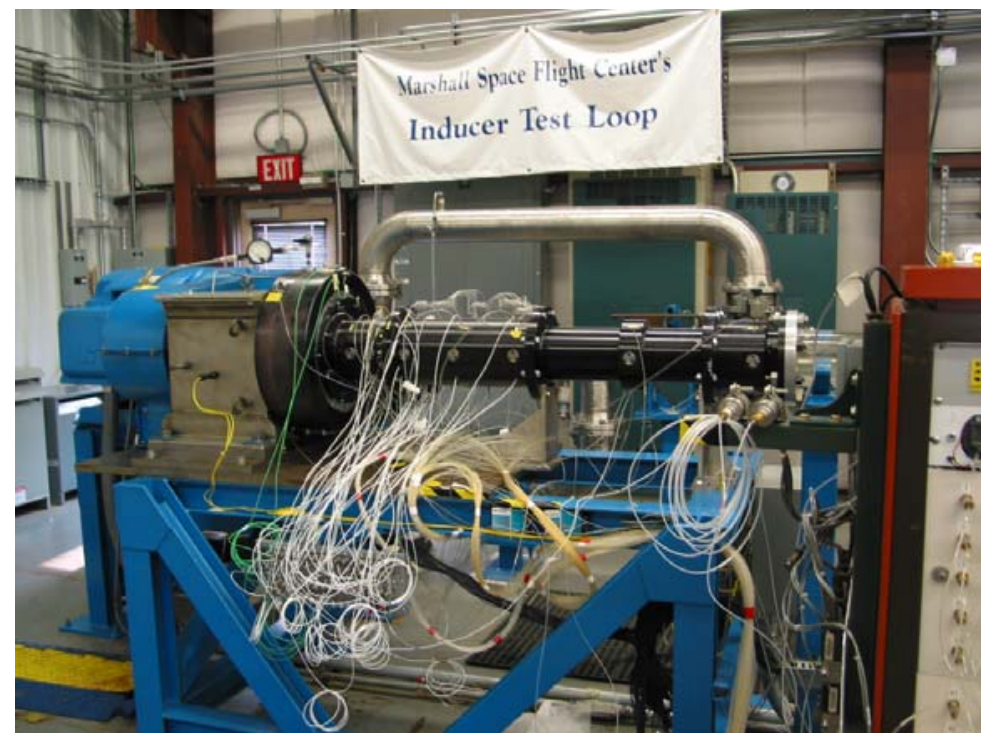

Subscale inducer test rig at MSFC

- Two 70-percent-scale models of the J-2S heritage Mk-29 LOX pump inducer

- Representative of full-scale heritage component with 2 leading-edge thicknesses bounding legacy hardware and drawing

- February 2008 test series by MSFC Fluid Dynamics Branch

- Objectives/Results

- Measure inducer head rise unsteady pressure, upstream velocity profile and exit swirl vs. flow coefficient and suction specific speed

- Mk-29 inducer failed to meet suction capability margin required and confirmed unacceptability of casting tolerances

- Water flow tests were confirmed by PPA-1A testing in LOX

- As a result, two-blade and three-blade unshrouded subscale configurations were water-flow tested at PWR, with acceptable performance. 


\section{Fuel Turbopump Subscale Inducer Testing}

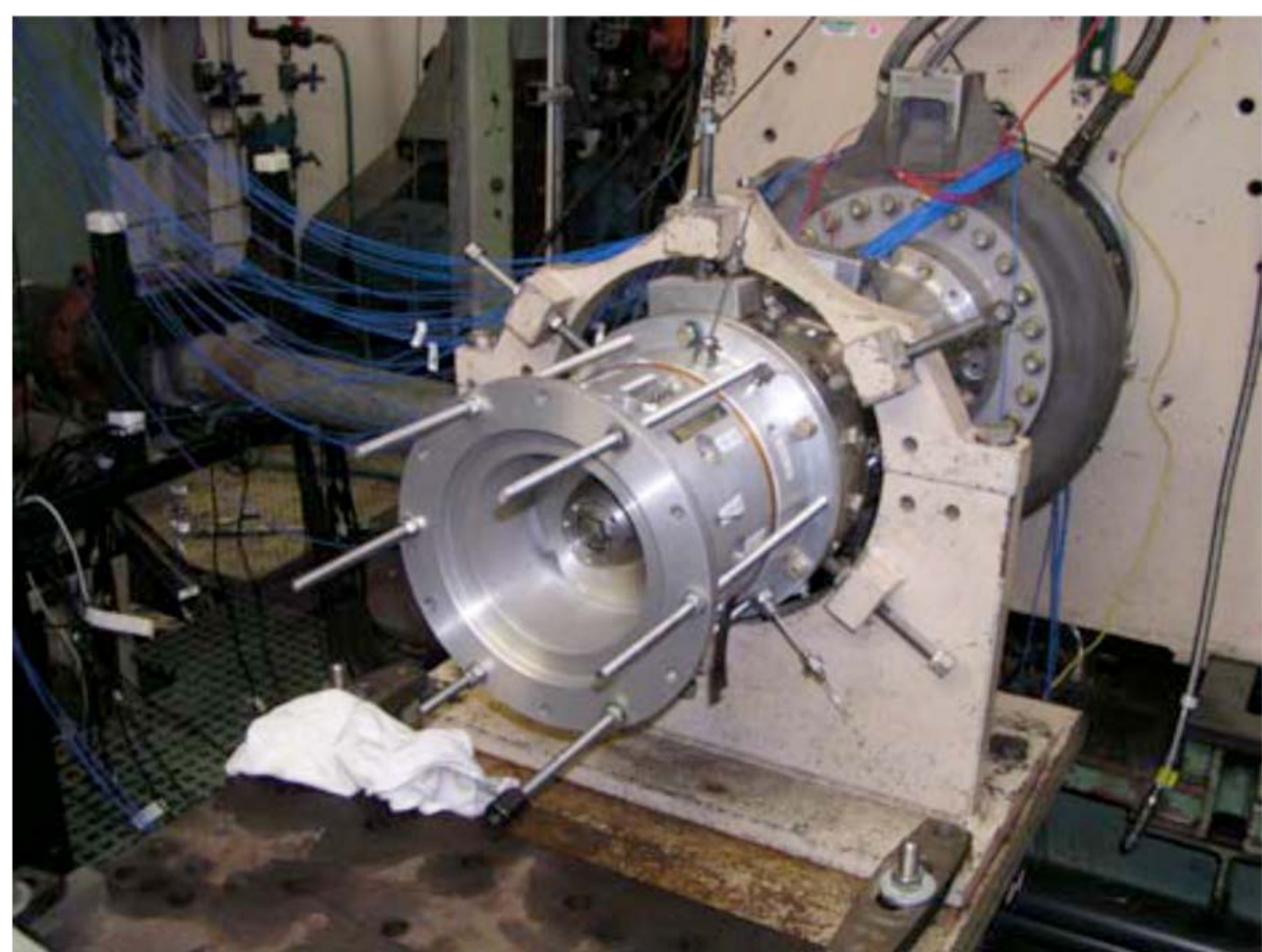

Heritage J-2 thin-bladed inducer configuration in test preparations at Pratt \& Whitney Rocketdyne

- January - February 2008

- Water flow testing of heritage J-2S FTP subscale thin bladed inducer (shown)

- Maximum/minimum allowable leading edge thicknesses

- Additional series for CDR configuration J-2X inducer

- Tests resulted in minor blade changes for final design testing in 2008 


\section{Heritage Fuel Air Turbine Testing}

- HFATT Risk Mitigation Task Priorities

- Determine steady and unsteady pressure loading on the 1st vane, 1st blade, and 2nd blade

- Anchor 2nd stage on-rotor CFD

- Anchor interstage cavity CFD

- Map turbine performance over a wide range of operating conditions, including spin start, engine start, $274 \mathrm{~K}$ and $294 \mathrm{~K}$ power levels and engine shutdown

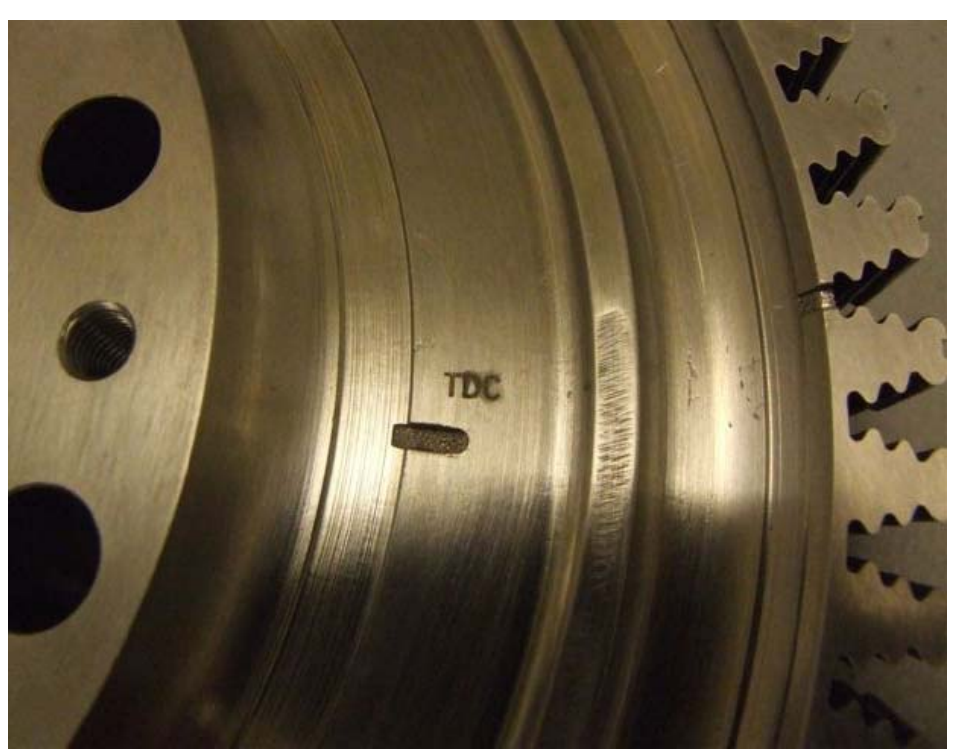

1st rotor with cavity pressure measurement pocket

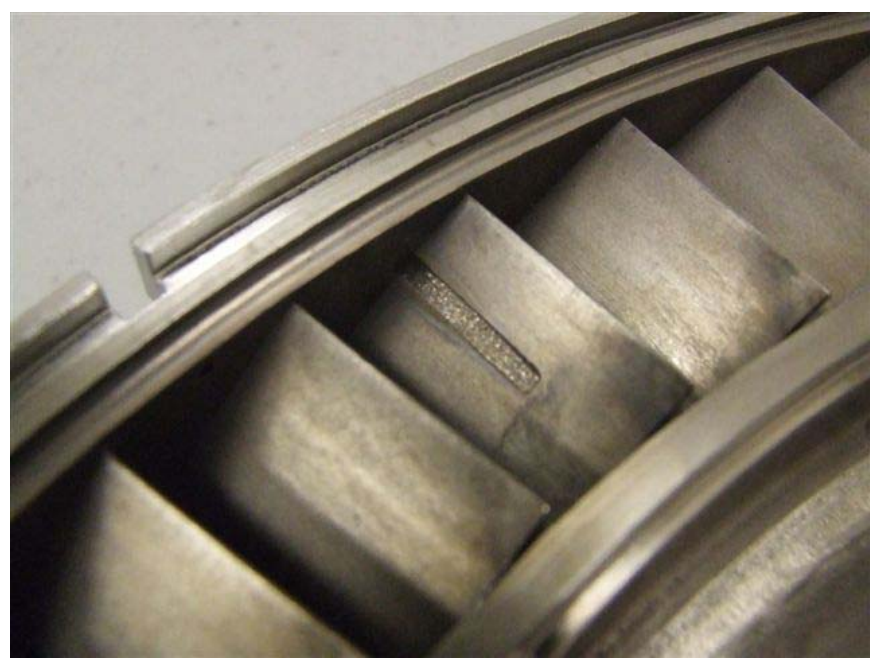

2nd vane with pressure measurement pocket

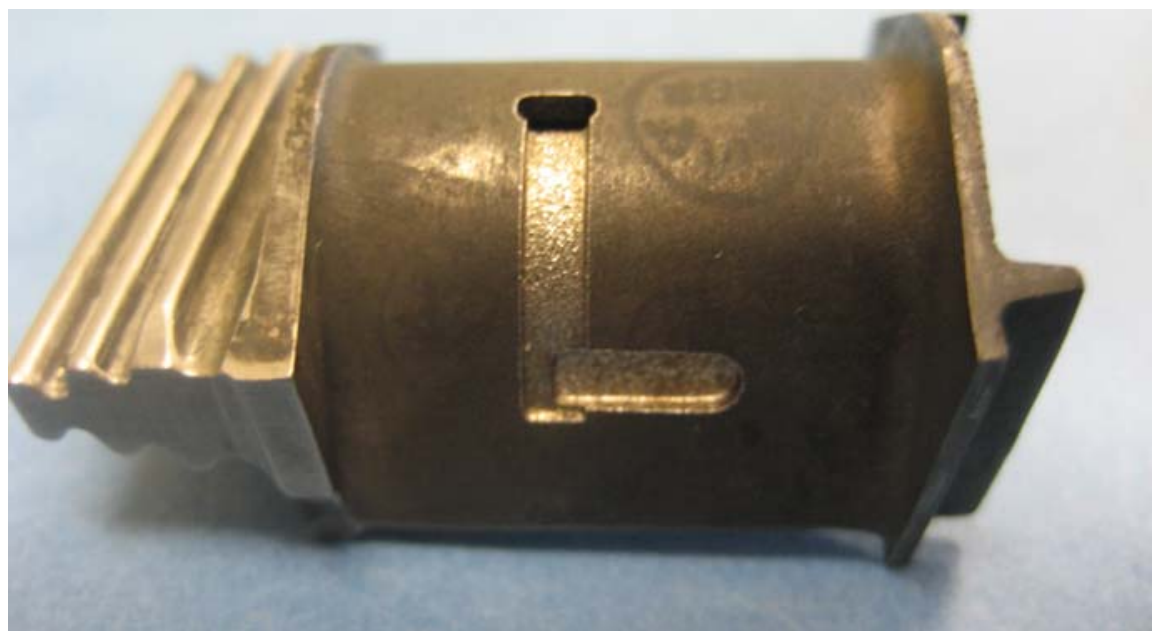

1st blade with pressure measurement pocket 


\section{Operability \& Integration: Interstage Integrated Compartment (ISIC) Internal Access GSE Needs}

Multiple level locations:

Aft Skirt Avionics area - up to $360^{\circ}$ access

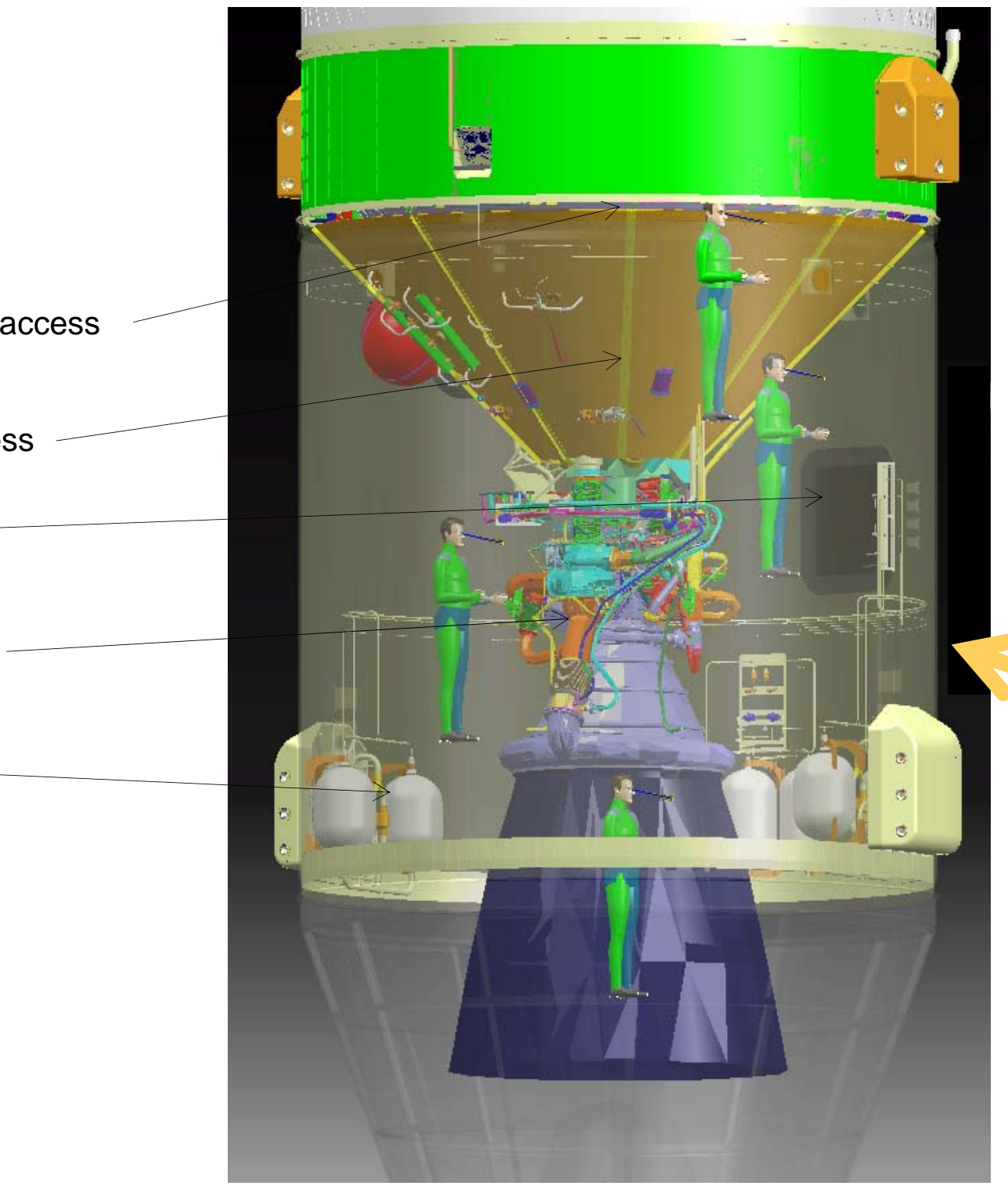

Thrust Cone area - up to $360^{\circ}$ access

Access hatch (one) - $\notin @ 315^{\circ}$

J-2X upper area - full $360^{\circ}$ access

RCS area - @ -Z, +Y, +Z 


\section{Operability \& Integration: J-2X Upper Engine Access}

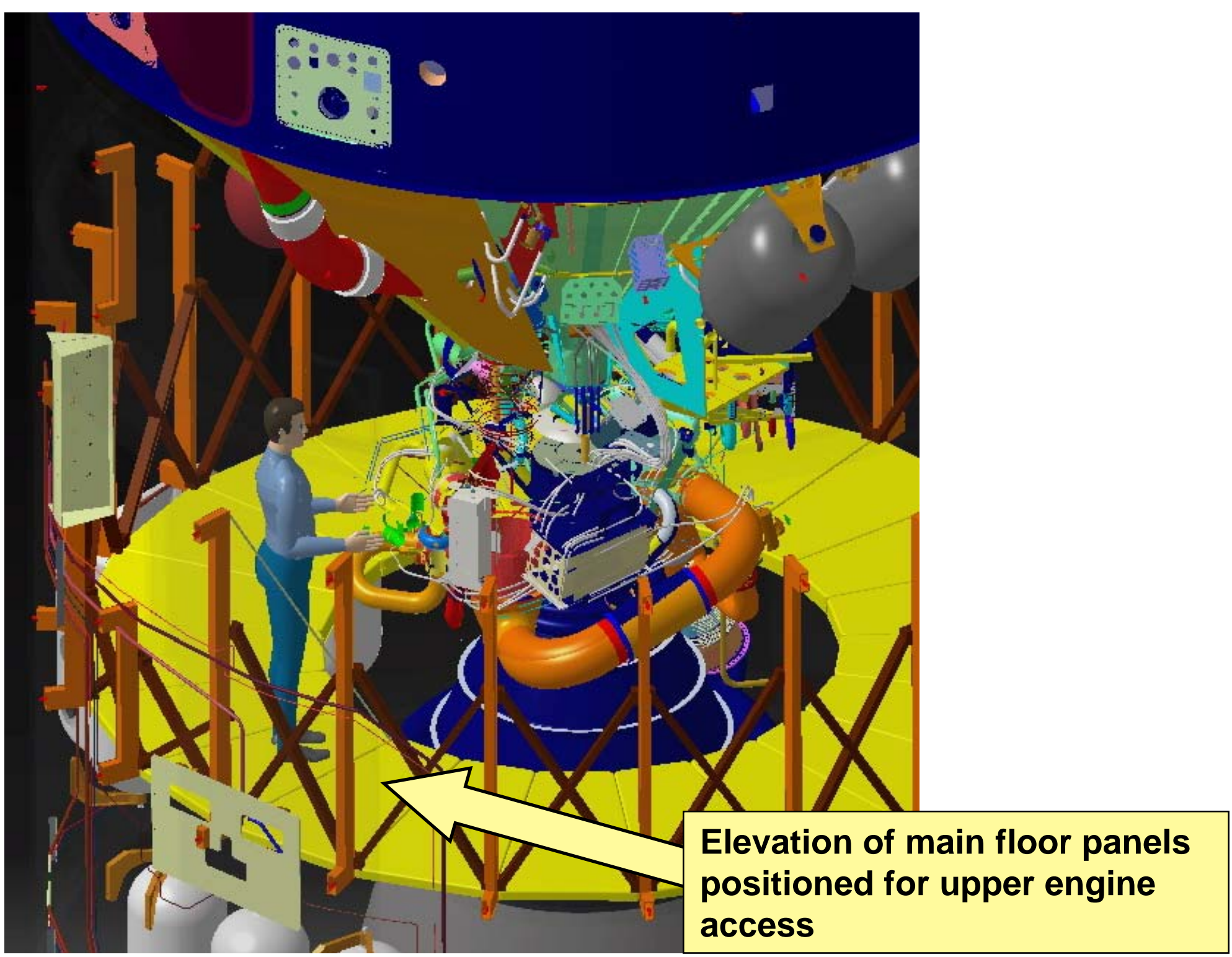




\section{J-2X Manufacturing Progress}

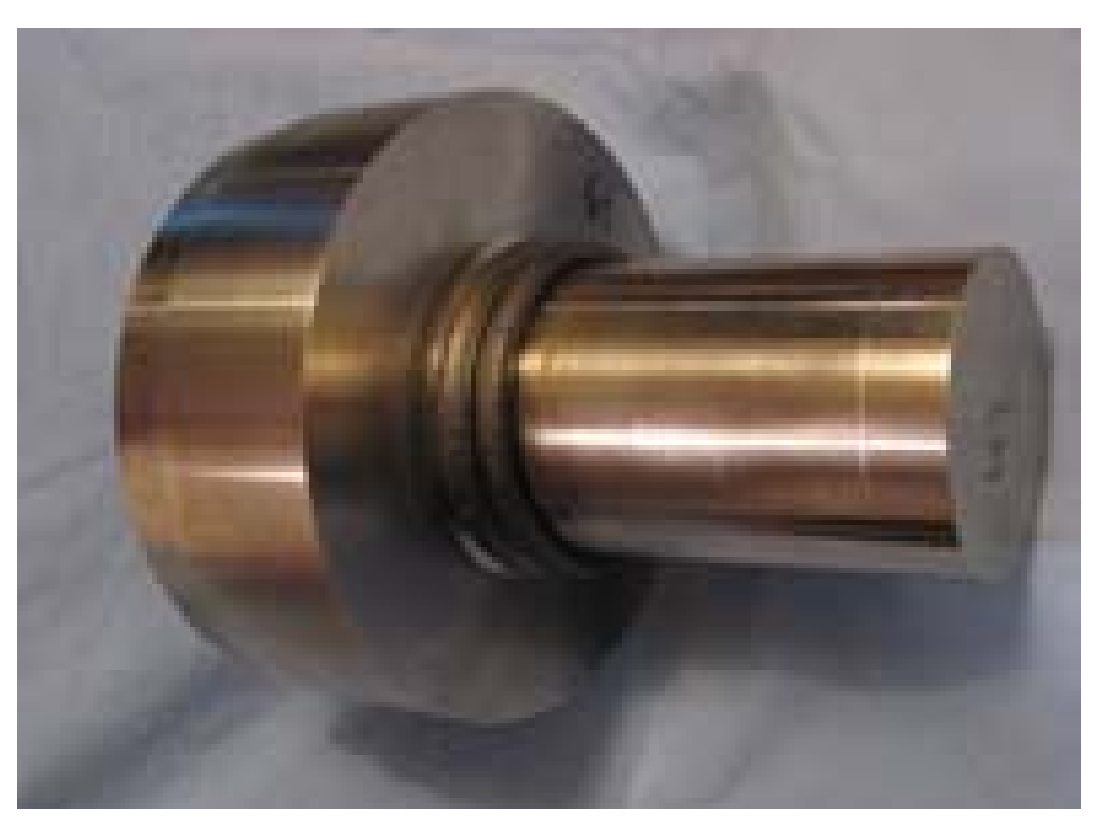

Inertia welding process demo sample

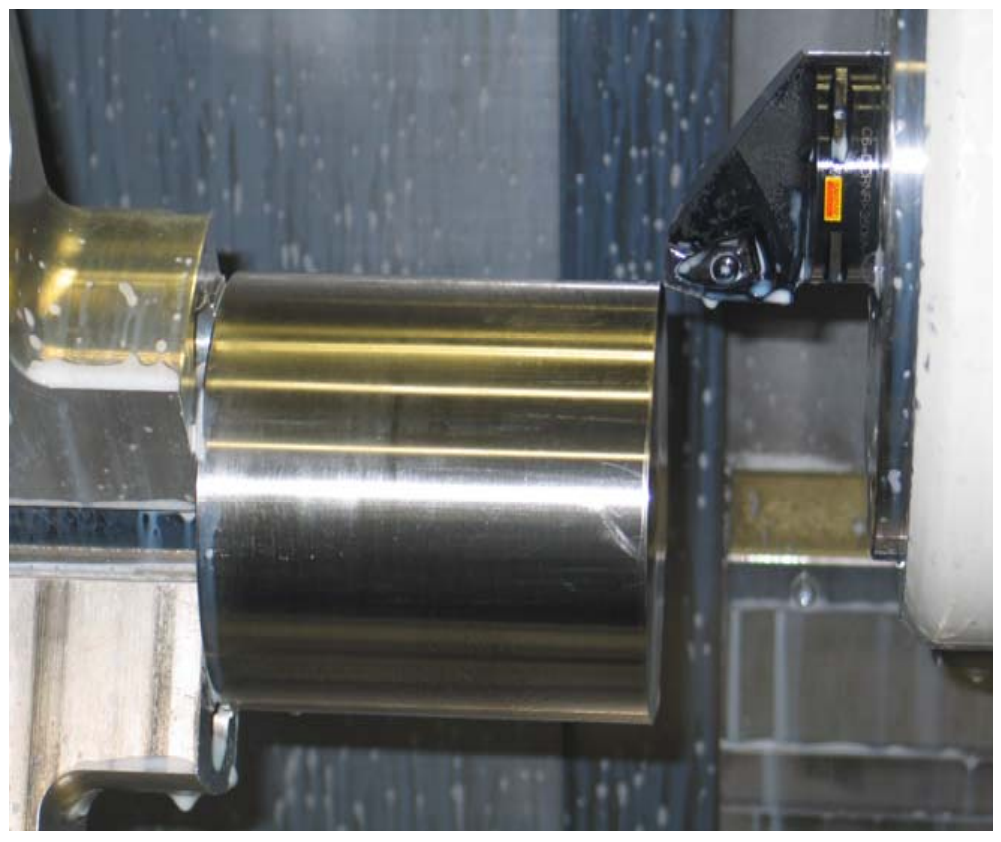

OTP shaft material before initial machining

- OTP fabrication demonstration (upper left) - inertial welding for shaft/first stage turbine disk

- OTP shaft machining (upper right) - for first OTP assembly, Powerpack Assembly \#2, spring 2010 test

- Casting trials for OTP discharge volute housing

- OTP fabrication demonstration - electron beam welding for first stage nozzle/turbine manifold installation

- Trial castings of Main Combustion Chamber forward manifold

- Spinning of Main Combustion Chamber liner 


\section{J-2X Manufacturing}

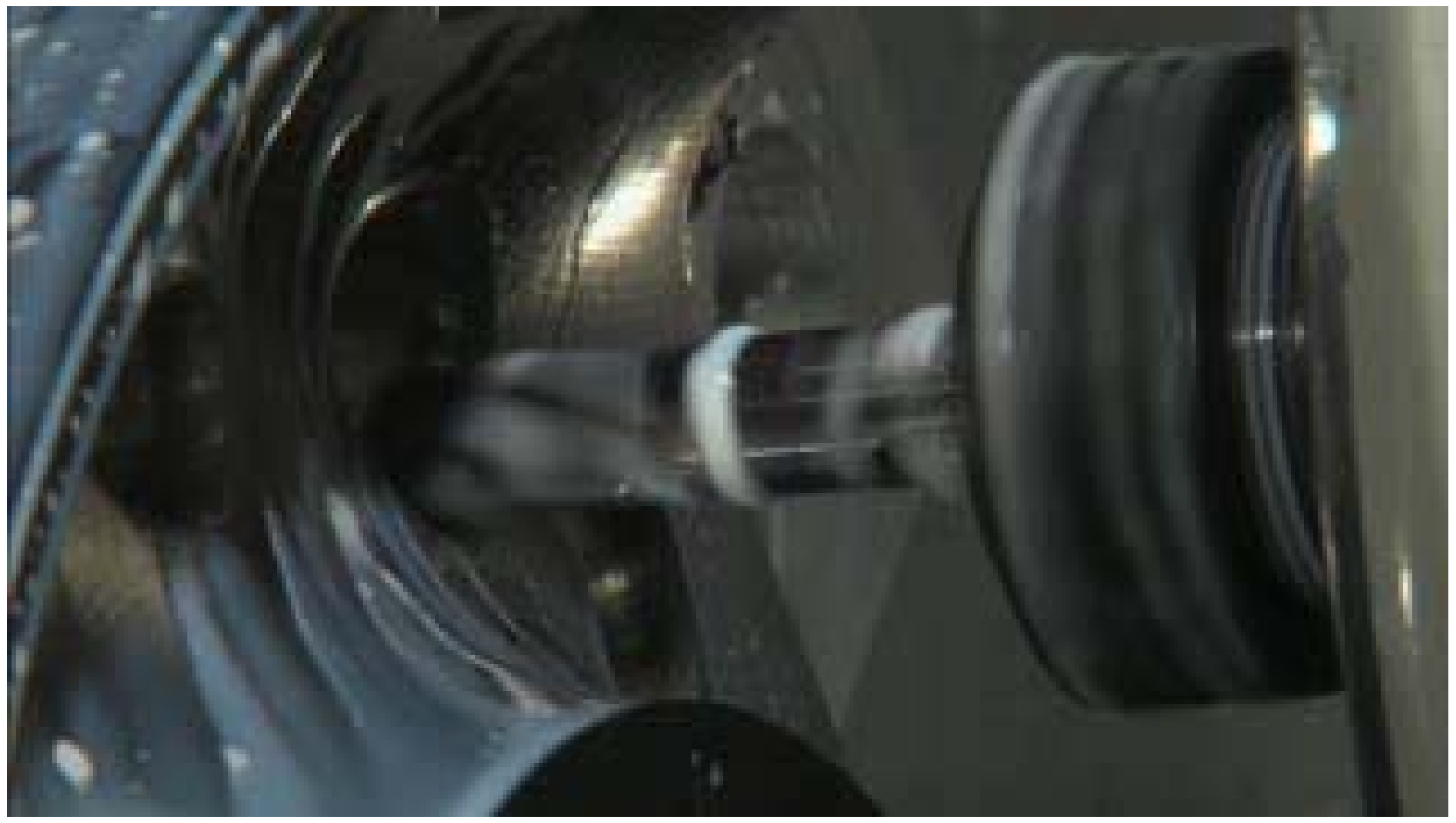




\section{Component Development Plan}
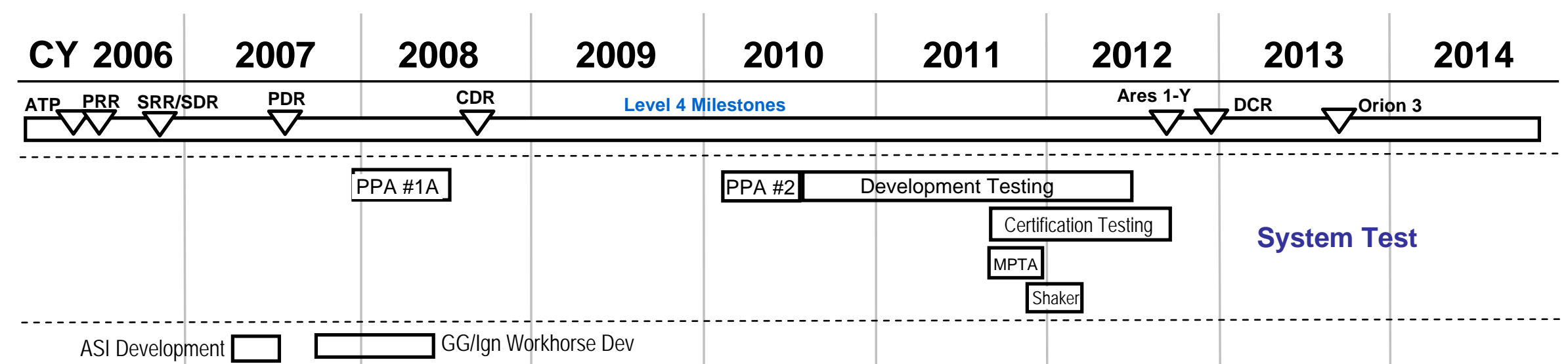

Subscale Inj Exist Subscale J-2X

Hdw Complete Injector $\square$

HW/SW Integration $\square \quad \square$ sW Flight Qual Test

Controller Flight DVT $\square$

SW Unit $\square \square$ Controller Qual

$\square$ Controller Breadboard

Insulation Thermal Vac Option $\square$

HEX \& Bellows Vibe Option

Hot Ducts \& Lines RVT

\section{$\square$ Fuel \& LOX Inlet RVT}

J-2X Gimbal Structure

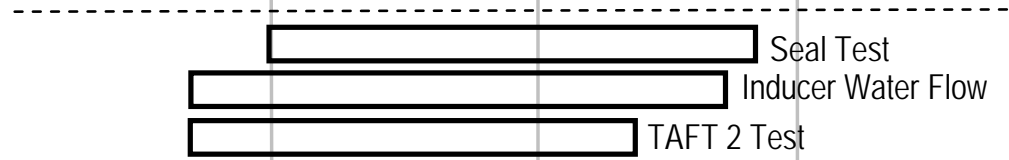

Fir Tree Damping
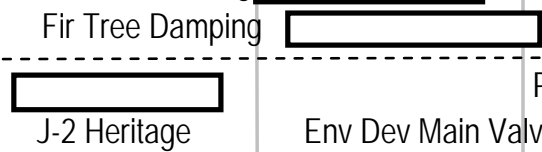

Env Dev Main Valves

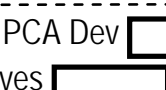

J-2 Heritag

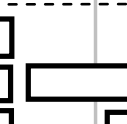

Hdw Char Ancillary $1^{\text {st }}$ Article Dev Testing

Combustion Devices

Controls

Turbomachinery

System Integration 


\section{J-2X Test Plan Schedule - Baseline}

\section{January 2008}

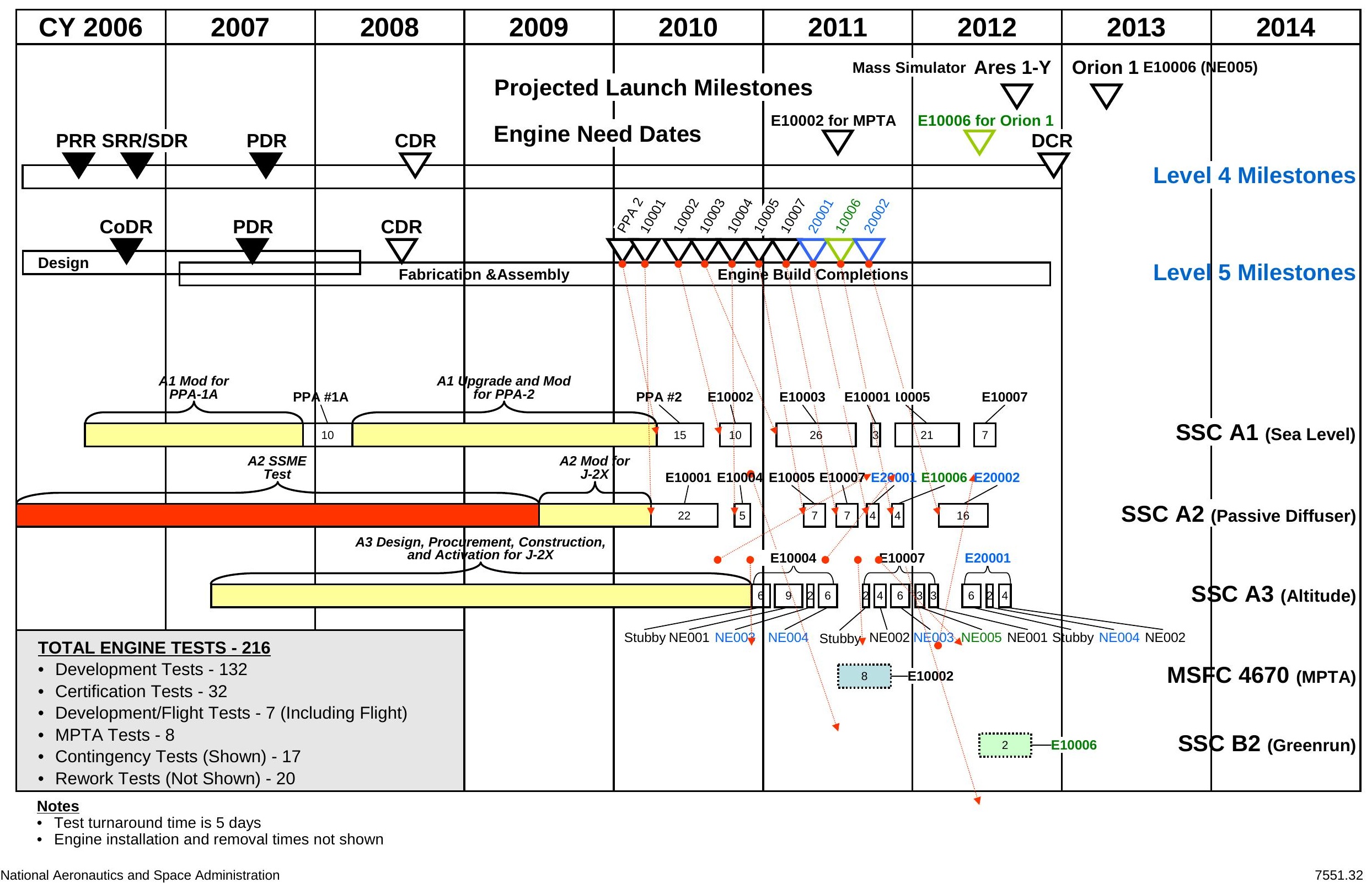




\section{The Way Forward}

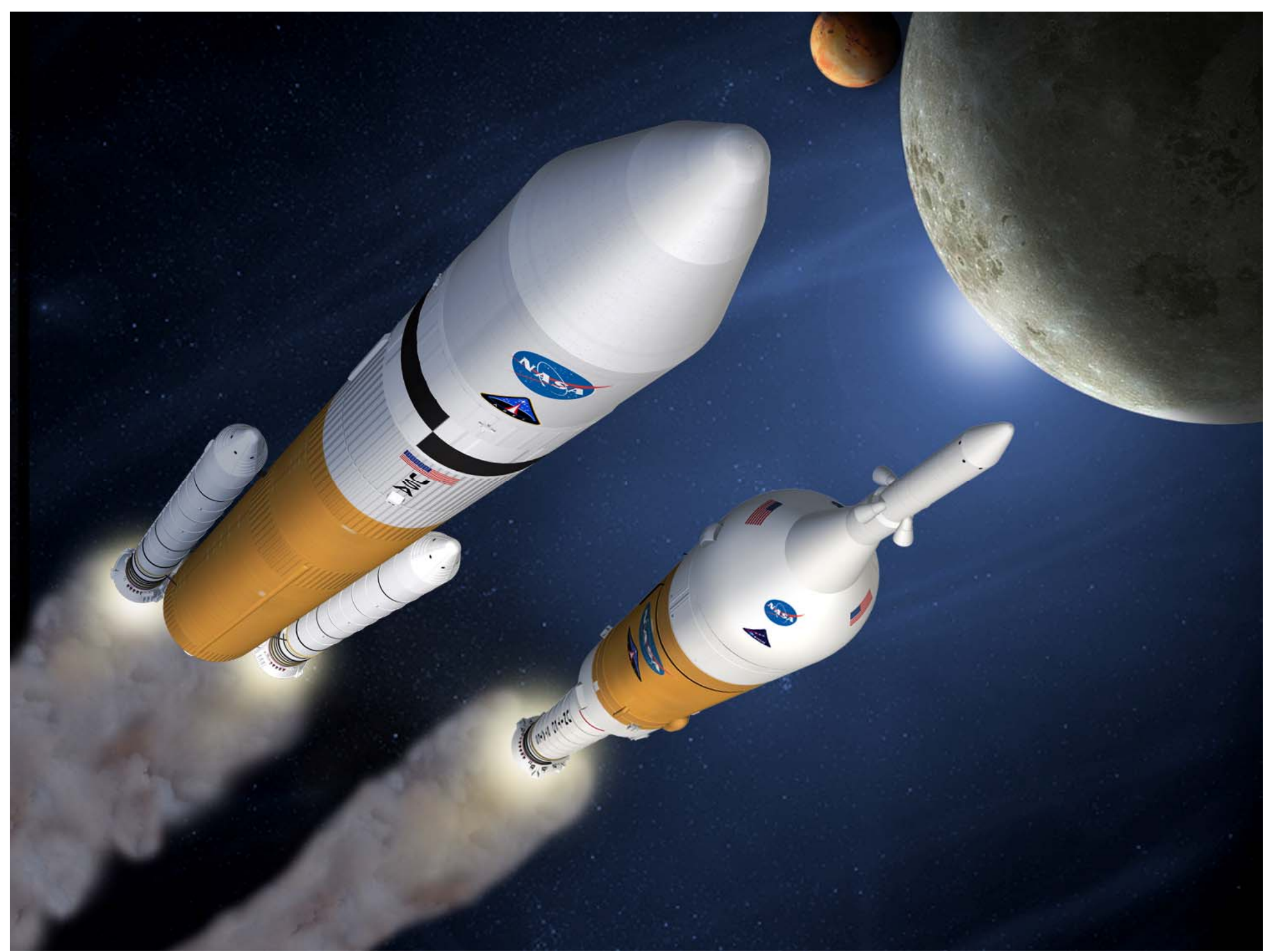

